\title{
Role of Presenilins in Neuronal Calcium Homeostasis
}

\author{
Hua Zhang, ${ }^{1 \star}$ Suya Sun, ${ }^{1 \star}$ An Herreman, ${ }^{2,3}$ Bart De Strooper, $, 2,3$ and Ilya Bezprozvanny ${ }^{1}$ \\ ${ }^{1}$ Department of Physiology, University of Texas Southwestern Medical Center at Dallas, Dallas, Texas 75390, ${ }^{2}$ Center for Human Genetics, Katholieke \\ Universiteit Leuven, B-3000 Leuven, Belgium, and ' ${ }^{2}$ epartment for Molecular and Developmental Genetics, VIB, Flanders Institute for Biotechnology, \\ B-3000 Leuven, Belgium
}

\begin{abstract}
Alzheimer's disease $(\mathrm{AD})$ is a progressive and irreversible neurodegenerative disorder. Familial $\mathrm{AD}(\mathrm{FAD})$ mutations in presenilins have been linked to calcium $\left(\mathrm{Ca}^{2+}\right)$ signaling abnormalities. To explain these results, we previously proposed that presenilins function as endoplasmic reticulum (ER) passive $\mathrm{Ca}^{2+}$ leak channels. To directly investigate the role of presenilins in neuronal ER Ca ${ }^{2+}$ homeostasis, we here performed a series of $\mathrm{Ca}^{2+}$ imaging experiments with primary neuronal cultures from conditional presenilin double-knock-out

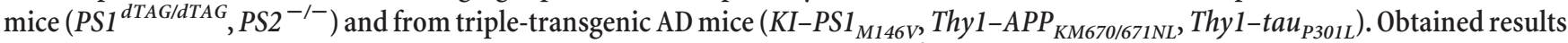
provided additional support to the hypothesis that presenilins function as $\mathrm{ER} \mathrm{Ca}^{2+}$ leak channels in neurons. Interestingly, we discovered that presenilins play a major role in $\mathrm{ER} \mathrm{Ca}^{2+}$ leak function in hippocampal but not in striatal neurons. We further discovered that, in hippocampal neurons, loss of presenilin-mediated $\mathrm{ER} \mathrm{Ca}^{2+}$ leak function was compensated by an increase in expression and function of ryanodine receptors (RyanRs). Long-term feeding of the RyanR inhibitor dantrolene to amyloid precursor protein-presenilin-1 mice $\left(\right.$ Thy1-APP $\left.{ }_{K M 670 / 671 N L}, T h y 1-P S 1_{L 166 P}\right)$ resulted in an increased amyloid load, loss of synaptic markers, and neuronal atrophy in hippocampal and cortical regions. These results indicate that disruption of $\mathrm{ER} \mathrm{Ca}^{2+}$ leak function of presenilins may play an important role in $\mathrm{AD}$ pathogenesis.
\end{abstract}

\section{Introduction}

Alzheimer's disease (AD) is the most common form of agerelated dementia in human beings over the age of 60 years. Most cases of $\mathrm{AD}$ are idiopathic, but the small fractions of $\mathrm{AD}$ cases are familial and characterized by an earlier onset and genetic inheritance. Mutations in presenilin-1 (PS1) and presenilin-2 (PS2) account for $\sim 40 \%$ of all known familial AD (FAD) cases in which a genetic cause has been identified (Tandon and Fraser, 2002). Presenilins are $50 \mathrm{kDa}$ proteins that contain nine transmembrane domains (Laudon et al., 2005; Spasic et al., 2006) and reside in the endoplasmic reticulum (ER) membrane (Annaert et al., 1999). Presenilins undergo endoproteolytic cleavage to N-terminal (NTF) and C-terminal (CTF) fragments. The complex of cleaved presenilins with nicastrin, aph-1, and pen-2 subunits moves from ER to plasma membrane, in which it functions as a $\gamma$-secretase, which cleaves the amyloid precursor protein (APP) and releases

Received March 26, 2010; revised April 30, 2010; accepted May 9, 2010.

This work was supported by the Alzheimer's Association, the Alzheimer's Disease Drug Discovery Foundation, a McKnight Brain Disorders Award, and National Institutes of Health Grant R01AG030746 (I.B.), a Methusalem grant from the Flemish government and the Katholieke Universiteit Leuven, the Fund for Scientific Research (Flanders, Belgium), Federal Office for Scientific Affairs Grant IUAP P6/43 (Belgium), and MEMOSAD (for Memory Loss in Alzheimer Disease: Underlying Mechanisms and Therapeutic Targets) Grant F2-2007-200611 of the European Union (B.D.S.). I.B. is a holder of the Carla Cocke Francis Professorship in Alzheimer's Research. We are grateful to Frank LaFerla for providing 3XTg mice and Mathias Jucker for providing the APPPS1 mice, Frank Wuytack for providing the SERCA2b antibody, Marek Michalek for providing CRT antibodies, Thomas Sudhof for providing the PSD95 antibodies and Lenti-Cre constructs, Roger Tsien for providing D1ER plasmid, Omar Nelson and Huarui Liu for help with making reagents, and Leah Benson for administrative assistance.

*H.Z. and S.S. contributed equally to this work.

Correspondence should be addressed to Dr. Ilya Bezprozvanny, Department of Physiology, ND12.200 University of Texas Southwestern Medical Center at Dallas, Dallas, TX 75390-9040. E-mail: Ilya.Bezprozvanny@ UTSouthwestern.edu.

DOI:10.1523/JNEUROSCI.1554-10.2010

Copyright $\odot 2010$ the authors $\quad 0270-6474 / 10 / 308566-15 \$ 15.00 / 0$ the amyloid $\beta$-peptide $(\mathrm{A} \beta)$, the principal constituent of the amyloid plaques in the brains of $\mathrm{AD}$ patients. Consistent with the role of presenilins as catalytic subunits of a $\gamma$-secretase (De Strooper et al., 1998; Wolfe et al., 1999), FAD mutations in presenilins affect APP processing.

In addition to changes in APP processing, many FAD mutations in presenilins result in deranged $\mathrm{Ca}^{2+}$ signaling, and growing evidence indicate that neuronal $\mathrm{Ca}^{2+}$ signaling disruptions may play an early and important role in $\mathrm{AD}$ pathogenesis (Bezprozvanny and Mattson, 2008). The connection between presenilins and $\mathrm{Ca}^{2+}$ signaling was initially uncovered when it was reported that fibroblasts from FAD patients release supranormal amounts of $\mathrm{Ca}^{2+}$ in response to inositol-1,4,5trisphosphate $\left(\mathrm{InsP}_{3}\right)$ (Ito et al., 1994). Similar results were obtained in experiments with cells expressing FAD mutant presenilins (Leissring et al., 1999a,b) and in cortical and hippocampal neurons from presenilin FAD mutant knock-in mice (Guo et al., 1999; Chan et al., 2000; Schneider et al., 2001; Stutzmann et al., 2004, 2006; Smith et al., 2005; Chakroborty et al., 2009). To explain these results, it has been suggested that mutant presenilins affect store-operated $\mathrm{Ca}^{2+}$ influx (Leissring et al., 2000; Yoo et al., 2000; Herms et al., 2003; Akbari et al., 2004), increase activity and/or expression of intracellular $\mathrm{Ca}^{2+}$ release channels, such as ryanodine receptors (RyanRs) (Chan et al., 2000; Smith et al., 2005; Stutzmann et al., 2006; Hayrapetyan et al., 2008; Rybalchenko et al., 2008) and $\mathrm{InsP}_{3}$ receptors ( $\mathrm{InsP}_{3} \mathrm{Rs}$ ) (Cai et al., 2006; Cheung et al., 2008), or modulate function of the smooth endoplasmic reticulum $\mathrm{Ca}^{2+}$-ATPase (SERCA) pump (Green et al., 2008). Based on results obtained in bilayer reconstitution electrophysiological experiments and $\mathrm{Ca}^{2+}$ imaging experiments with mouse embryonic fibroblasts (MEFs) from PS double-knock-out (DKO) mice, we 
previously suggested that presenilins function as passive $\mathrm{ER} \mathrm{Ca}^{2+}$ leak channels that control steady-state $\mathrm{ER} \mathrm{Ca}^{2+}$ levels (Tu et al., 2006). We also found that many FAD mutations in presenilins

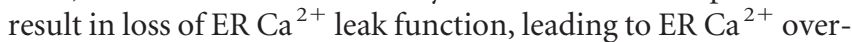
load and supranormal $\mathrm{Ca}^{2+}$ release from the ER (Tu et al., 2006; Nelson et al., 2007, 2010). The ER $\mathrm{Ca}^{2+}$ leak function of presenilins was independent of their $\gamma$-secretase function because it could be rescued by PS1-D257A mutant, which lacks $\gamma$-secretase activity, and it was maintained in Aph-1 triple-knock-out MEF cells, which lack $\gamma$-secretase but express full-length presenilins (Tu et al., 2006).

To directly investigate the role of presenilins in neuronal ER $\mathrm{Ca}^{2+}$ homeostasis, we here performed a series of $\mathrm{Ca}^{2+}$ imaging experiments with primary neuronal cultures from conditional presenilin double-knock-out mice (PScDKO mice) (PS1 $1^{d T A G / d T A G}$, $\left.P S 2^{-1-}\right)$ and from triple-transgenic $\mathrm{AD}$ mice $(3 \mathrm{xTg}$ mice) (KI$P S 1_{M 146 V}$, Thy1-APP ${ }_{K M 670 / 671 N L}$, Thy1-tau ${ }_{P 301 L}$ ) (Oddo et al., 2003). Obtained results supported the hypothesis that presenilins function as $\mathrm{ER} \mathrm{Ca}^{2+}$ leak channels in neurons. We further discovered that a loss of ER $\mathrm{Ca}^{2+}$ leak function of presenilins in hippocampal neurons was compensated by increased expression and activity of RyanRs. Furthermore, long-term feeding of a double-transgenic AD mice (APPPS1 mice) (Thy1-APP ${ }_{K M 670 / 671 N L}$, Thy1-PS1 $1_{L 166 P}$ ) (Radde et al., 2006) with the RyanR inhibitor dantrolene resulted in increased amyloid load, loss of synaptic markers, and neuronal atrophy in hippocampal and cortical regions of these mice. Our results provide new evidence that disruption of $\mathrm{ER} \mathrm{Ca}^{2+}$ leak function of presenilins and resulting neuronal $\mathrm{Ca}^{2+}$ dyshomeostasis play an important role in $\mathrm{AD}$ pathogenesis. Our results obtained with the three different presenilin genetic mouse models (knockin, conditional knock-out, and transgenic) also provide the beginning of a common foundation for the currently contradictory view on the role that presenilins play in neuronal $\mathrm{Ca}^{2+}$ homeostasis.

\section{Materials and Methods}

Transgenic mouse lines. The PScDKO mice ( $\left.P S 1^{d T A G / d T A G}, P S 2^{-/-}\right)$were generated by crossing $P S 1^{d T A G / d T A G}$ mice with $P S 2^{-/-}$mice (Herreman et al., 1999). $P S 1^{d T A G / d T A G}$ mice were generated by knockin strategy. The first exon of PSEN1 gene was surrounded by loxP sites (supplemental Fig. $1 \mathrm{~A}$, available at www.jneurosci.org as supplemental material). In addition, a double tag encoding for calmodulin binding protein followed by $3 x$ Flag epitope tag was inserted immediately after the ATG start codon of PSEN1 (supplemental Fig. $1 \mathrm{~A}$, available at www.jneurosci.org as supplemental material). The generation and characterization of 3xTg mice (KI$P S 1_{M 146 V}$, Thy1-APP ${ }_{K M 670 / 671 N L}$, Thy1-tau P301L $\left._{1}\right)$ has been described previously (Oddo et al., 2003). The wild-type (WT) mice of the same mixed background strain (C7BL/6;129X1/SvJ;129S1/Sv) was used as a control for experiments with $3 x \mathrm{Tg}$ mice. $3 \mathrm{xTg}$ mice and control WT mice were kindly provided by Frank LaFerla (University of California, Irvine, Irvine, CA). The generation and characterization of APPPS1 mice (Thy1-APP ${ }_{K M 670 / 671 N L}$, Thy1-PS1 $1_{L 166 P}$ ) has been described previously (Radde et al., 2006). The APPPS1 mice were kindly provided by Mathias Jucker (University of Tübingen, Tübingen, Germany). The three transgenic mouse lines and WT mice were housed in a pathogen-free facility in a temperature-controlled room at $22-24^{\circ} \mathrm{C}$ with a $12 \mathrm{~h}$ light/dark cycle and were fed a standard laboratory chow diet and double-distilled water ad libitum. All procedures involving mice were approved by the Institutional Animal Care and Use Committee of the University of Texas Southwestern Medical Center at Dallas, in accord with the National Institutes of Health Guidelines for the Care and Use of Experimental Animals.

Antibodies. Anti-CTF-PS1 monoclonal antibody (mAb) (MAB5232) and anti-actin mAb (MAB1501) were from Millipore Bioscience Research Reagents, anti-FLAG mAb (F3165) was from Sigma, anti-RyanR mAb (MA3-925) was from Affinity BioReagents, polyclonal antibody for
$\mathrm{InsP}_{3} \mathrm{R} 1$ (T443) was described previously (Kaznacheyeva et al., 1998), polyclonal antibody for SERCA2b was provided by Dr. Frank Wuytack (Katholieke Universiteit Leuven, Leuven, Belgium), monoclonal antibody for postsynaptic density 95 (PSD95) (MA1-045) was purchased from Thermo Fisher Scientific, neuronal-specific nuclear protein (NeuN) mAb (MAB377) was from Millipore Corporation, dopamine and cAMP-regulated phosphoproteins-32 (DARPP-32) mAb (catalog \#2306) was from Cell Signaling Technology, anti-A $\beta$ 6E10 mAb (SIG39300) was from Covance, Alexa Fluor-488 or Alexa Fluor-594 antirabbit and anti-mouse secondary antibodies (A21121, A11012, and A11008) were from Invitrogen, HRP-conjugated anti-rabbit and antimouse secondary antibodies (115-035-146 and 111-035-144) were from Jackson ImmunoResearch, and biotinylated anti-mouse IgG reagent was from Vector Laboratories (M.O.M. kit, BMK-2202). For Western blotting, analysis proteins were resolved on $6 \%$ (for RyanR and $\mathrm{InsP}_{3} \mathrm{R} 1$ ), $10 \%$ (for actin and SERCA2B), or 12\% (for PS1) SDS-PAGE gels, transferred to nitrocellulose paper, and probed with the corresponding primary and secondary antibodies.

Lentivirus generation and infection of primary neuronal cultures. Shuttle plasmid constructs encoding nuclear localization signal (NLS)-green fluorescent protein (GFP)-Cre and NLS-GFP were provided by Thomas Südhof (Stanford University, Stanford, CA). Lenti-Cre and Lenti-GFP viruses were generated by cotransfection of shuttle vectors with human immunodeficiency virus- 1 packaging vector 8.9 and vesicular stomatitis virus glycoprotein $\mathrm{G}$ envelope glycoprotein plasmids into the packaging cell line HEK293T as we described previously (Tang et al., 2009). The generated viral stocks were aliquoted into $1 \mathrm{ml}$ tubes, immediately frozen in liquid nitrogen, and stored at $-80^{\circ} \mathrm{C}$. Before use, the aliquots of generated lentiviruses were thawed and warmed in the $37^{\circ} \mathrm{C}$ incubator. Each batch of generated Lenti-Cre and Lenti-GFP lentiviruses was tested in pilot cortical neuronal culture infection experiments, and the titer with minimal toxicity and maximum infection efficiency $(>95 \%)$ was used in all experiments.

The hippocampal and striatal cultures of PScDKO, 3xTg, and WT mice were established from postnatal day $0-1$ pups and maintained in culture as we described previously (Tang et al., 2005; Zhang et al., 2006). Lenti-Cre and Lenti-GFP viruses were added to PScDKO cultures at day in vitro 4 (DIV4). Wild-type PS1 and mutant PS1 constructs (L166P, $\Delta \mathrm{E} 9, \mathrm{M} 146 \mathrm{~V}, \mathrm{D} 257 \mathrm{~A}$, and D385A) were amplified by PCR using constructs in pcDNA3 (Tu et al., 2006; Nelson et al., 2007) and cloned into lentiviral shuttle vector. An N-terminal hemagglutinin (HA) tag was added to all lentiviral PS1 constructs by PCR. Control-short-hairpin RNA interference (Ctrl-shRNAi) (SHC002) and RyR-shRNAi (SHCLNG_ NM_009109, TRCN0000103010) lentivirus shuttle constructs were obtained from Sigma. Lenti-PS1 and Lenti-shRNAi viruses were generated by following the same procedures as for Lenti-Cre and Lenti-GFP viruses. The Lenti-PS1 rescue viruses were added to Lenti-Cre-infected PScDKO hippocampal neuronal cultures at DIV6. Lenti-shRNAi viruses were added to WT and 3xTg hippocampal neuronal cultures at DIV6.

Fura-2 $\mathrm{Ca}^{2+}$ imaging experiments. Fura- $\mathrm{Ca}^{2+}$ imaging experiments with DIV12 or DIV13 hippocampal and striatal cultures were performed as described previously (Tang et al., 2005; Tu et al., 2006). Briefly, the cells were maintained in artificial CSF (aCSF) (in mM: $140 \mathrm{NaCl}, 5 \mathrm{KCl}, 1$ $\mathrm{MgCl}_{2}, 2 \mathrm{CaCl}_{2}$, and 10 HEPES, pH 7.3). Fura-2 $340 \mathrm{~nm} / 380 \mathrm{~nm}$ ratio images were collected every $2 \mathrm{~s}$ for the duration of the experiment using a DeltaRAM-X illuminator, an IC-300 camera, and IMAGEMASTER PRO software (all from Photon Technology International, Inc.). The region of interest (ROI) used in the image analysis corresponded to the entire cell soma. For caffeine experiments, $25 \mathrm{~mm}$ caffeine in aCSF was applied. For ionomycin (IO) experiments, the cells were first washed with the $\mathrm{Ca}^{2+}$-free aCSF (omitted $\mathrm{CaCl}_{2}$ from aCSF and supplemented with $100 \mu \mathrm{M}$ EGTA) for $30 \mathrm{~s}$ or $2 \mathrm{~min}$ as indicated, followed by addition of $5 \mu \mathrm{M} \mathrm{IO}$. For $\mathrm{KCl}$ refill experiments, the neurons were first challenged with $15 \mathrm{~mm} \mathrm{KCl}$ for $1 \mathrm{~min}$ in aCSF and then perfused with $\mathrm{Ca}^{2+}$-free aCSF for $30 \mathrm{~s}$ or $2 \mathrm{~min}$ as indicated, followed by addition of $5 \mu \mathrm{m}$ IO. In dantrolene experiments, $50 \mathrm{~nm}$ dantrolene was added to the culture medium at DIV7, DIV9, and DIV11, and $\mathrm{Ca}^{2+}$ imaging experiments were performed at DIV13. All $\mathrm{Ca}^{2+}$ imaging experiments were done in room temperature. In caffeine experiments, maximal amplitude (peak) re- 
sponse was determined from fura- $2340 \mathrm{~nm} / 380 \mathrm{~nm}$ ratios. The size of the ER $\mathrm{Ca}^{2+}$ pool was calculated by integrating an area under the IOinduced fura- $2 \mathrm{Ca}^{2+}$ response curve as we described previously (Tu et al., 2006). $\mathrm{IO}_{30}$ and $\mathrm{IO}_{120}$ correspond to the size of IO-releasable $\mathrm{Ca}^{2+}$ pool after $30 \mathrm{~s}$ and $120 \mathrm{~s}$ incubation in $\mathrm{Ca}^{2+}$-free aCSF, respectively. There was no significant difference in basal fura- 2 ratio values in different groups of neurons before addition of ionomycin. The only exception were neurons infected with PS1- $\Delta$ E9 virus, which yielded higher basal $\mathrm{Ca}^{2+}$ levels and increased fura- 2 ratios, presumably because this mutant acts as "superleaky" channel in the ER membrane (Tu et al., 2006).

D1ER $\mathrm{Ca}^{2+}$ imaging experiments. D1ER expression plasmid was kindly provided by Dr Roger Tsien (University of California, San Diego, La Jolla, CA) (Palmer et al., 2004). D1ER is a fluorescence resonance energy transfer (FRET)-based cameleon $\mathrm{Ca}^{2+}$ indicator composed of enhanced cyan fluorescent protein (ECFP) and citrin fluorescent protein separated by a linker encoding calmodulin (CaM) and CaM-binding M13 peptide sequence (Palmer et al., 2004; McCombs and Palmer, 2008). Calreticulin (CRT) targeting sequence (MLLPVLLLGLLGAAAD) was added to $\mathrm{N}$ terminus and ER retention sequence (KDEL) was added to the $\mathrm{C}$ terminus of D1ER protein to facilitate ER targeting and retention.

WT and PS DKO MEF cells were described previously (Herreman et al., 2000; Tu et al., 2006). WT and DKO MEF cells were transfected with D1ER plasmid using Lipofectamine 2000. DIV7 WT and 3xTg primary hippocampal neuronal cultures were transfected with D1ER plasmid using the polyethylenimine method. Imaging experiments with transfected MEF cells and hippocampal neurons were performed $48 \mathrm{~h}$ after D1ER transfection using Deltavision RT wide-field epifluorescence deconvolution microscope (Applied Precision) equipped with a Photometrics CoolSNAPHQ monochromatic digital camera (Roper Scientific) controlled by the SoftWorx image acquisition software package (Applied Precision). The filter sets used for FRET imaging experiments were CFPx $436 \mathrm{~nm} / 10 \mathrm{~nm}$ and yellow fluorescent protein (YFPx) $492 \mathrm{~nm} / 18 \mathrm{~nm}$ for excitation (x) and CFPm $465 \mathrm{~nm} / 30 \mathrm{~nm}$ and YFPm $535 \mathrm{~nm} / 30 \mathrm{~nm}$ for emission (m). The series of three images CFPx/CFPm (CFP), YFPx/ YFPm (YFP), and CFPx/YFPm (FRET) were acquired every $25 \mathrm{~s}$. After collection of initial data points ( $100 \mathrm{~s}$ ), the cells were washed with $\mathrm{Ca}^{2+}$ free aCSF and transferred to $\mathrm{Ca}^{2+}$-free aCSF containing $2 \mu \mathrm{M}$ of the SERCA pump inhibitor thapsigargin for $600 \mathrm{~s}$ to deplete the ER $\mathrm{Ca}^{2+}$ stores. After thapsigargin treatment, the cells were exposed to $5 \mu \mathrm{M} \mathrm{IO}$. At the conclusion of each experiment, the FRET/CFP ratio signals were calibrated in the presence $5 \mu \mathrm{M}$ ionomycin using a series of calibration buffers (in mM: $125 \mathrm{KCl}, 25 \mathrm{NaCl}, 10$ HEPES, and 0.8 EGTA, pH 7.3) with free $\mathrm{Ca}^{2+}$ clamped to defined concentrations $(1 \mu \mathrm{M}, 10 \mu \mathrm{M}, 50 \mu \mathrm{M}, 100$ $\mu \mathrm{M}, 200 \mu \mathrm{M}, 400 \mu \mathrm{M}, 800 \mu \mathrm{M}$, and $5 \mathrm{mM})$. The free $\mathrm{Ca}^{2+}$ concentration in the calibration buffers was calculated by WEBMAXC STANDARD program. Calibration and analysis of the data were performed using NIH Image J software. The $\mathrm{ER} \mathrm{Ca}^{2+}$ concentration was calculated from FRET/ CFP ratio data for each cell using corresponding empirical calibration curves for the same type of cells.

Drug delivery and histological analysis. Dantrolene was delivered to APPPS1 and WT mice by using an approach that we used previously for dantrolene evaluation in spinocerebellar ataxia type 3 (SCA3) and type 2 (SCA2) mice (Chen et al., 2008; Liu et al., 2009). Briefly, six APPPS1 hemizygous mice and six WT mice were fed with $100 \mu \mathrm{g}$ of dantrolene suspended in $50 \mu \mathrm{l}$ of PBS with $2 \%$ corn flour, resulting in the final dose of $5 \mathrm{mg} / \mathrm{kg}$. The control group of six APPPS1 hemizygous mice and six WT mice were fed with $2 \%$ corn flour in PBS. All mice were fed orally twice a week from 2 to 8 months of age. At the conclusion of dantrolene feeding, all mice were terminally anesthetized and perfused transcardially with $30 \mathrm{ml}$ of ice-cold PBS, followed by $50 \mathrm{ml}$ of fixative (4\% paraformaldehyde in 0.1 м PBS, pH 7.4) as we described previously (Chen et al., 2008; Liu et al., 2009; Tang et al., 2009). All brains were removed from the skull, postfixed overnight at $4^{\circ} \mathrm{C}$ in $4 \%$ paraformaldehyde, and equilibrated in $20-30 \%(\mathrm{w} / \mathrm{v})$ sucrose in PBS. The brains were sliced to $30-$ $\mu \mathrm{m}$-thick coronal sections using SM2000R sliding microtome (Leica).

For $\beta$-amyloid plaque staining, the $30 \mu \mathrm{m}$ coronal sections from APPPS1 mice spaced throughout the forebrain were stained with $6 \mathrm{E} 10$ anti-A $\beta$ mAb (1:1000 dilution), followed by staining with Alexa Flour488 secondary anti-mouse IgG (1:2000 dilution). The quantitative anal- ysis of amyloid load was performed blindly using the Isocyte laser scanner system (Molecular Devices). The average area of the amyloid plaques (AREA), the average intensity of fluorescent signal in the plaques (IINT1), and the number of plaques was calculated automatically for each slice by using proprietary image analysis software (Molecular Devices). Twenty coronal sections from each of the 12 APPPS1 mice were quantified for the analysis, and the data were averaged within dantrolene-fed and control groups.

The immunostaining experiments were performed as we described previously (Chen et al., 2008; Liu et al., 2009; Tang et al., 2009). The hippocampal sections were stained with PSD $95 \mathrm{mAb}$ and Alexa Fluor488 anti-mouse IgG. The hippocampal nuclei were stained with propidium iodide (PI). The striatal sections were stained with DARPP-32 $\mathrm{mAb}$ and Alexa Fluor-594 anti-mouse IgG. The images from hippocampal and striatal sections were collected using a Carl Zeiss Axoivert 100M confocal microscope. The striatal sections were also stained with anti$\mathrm{NeuN} \mathrm{mAb}$ and biotinylated anti-mouse IgG. Signal was amplified with an ABC Elite kit (Vector Laboratories) and detected with diaminobenzidine (Vector Laboratories). The Bielschowsky silver staining was performed on four sections for each APPPS1 mice and WT mice by following published procedures (Schwab et al., 2004). Briefly, the sections were closed and mounted to slides. The slides were placed in $0.1 \%$ silver nitrate solution, containing citric acid in a $65^{\circ} \mathrm{C}$ water bath for 7 min. The slides were rinsed in two changes of $\mathrm{ddH}_{2} \mathrm{O}$, followed by rinse in $95 \%$ ethanol, and then rinsed with two changes of absolute ethanol. All slides were immersed in filtered $2.5 \%$ gum mastic ethanol solution for 5 min and then put into developing solution ( $10 \mathrm{ml}$ of $2.5 \%$ gum mastic ethanol solution, $30 \mathrm{ml}$ of $1.7 \%$ hydroquinone, plus $0.9 \mathrm{ml}$ of $1 \%$ silver nitrate) in a $65^{\circ} \mathrm{C}$ water bath until a dark brown color developed $(\sim 12$ min). The slides were rinsed in water, dehydrated, and mounted. The pictures for NeuN and silver staining were taken using the Nikon Eclipse $80 \mathrm{i}$ microscope.

For quantification of PSD95 density, confocal data were collected using $40 \times$ objective with a Carl Zeiss 100M microscope. The collected data were exported in tiff file format using a Carl Zeiss confocal software. The tiff file containing PSD95 staining signal (green channel) was imported into NIH ImageJ. The ROI $200 \times 200$ pixels was randomly selected in $\mathrm{NIH}$ ImageJ, and the software automatically calculated the number of PSD95 puncta and area of PSD95-positive pixels in the selected ROI. For quantification of neurite density, the images of the hippocampal slides stained with Bielschowsky silver staining method were taken using a $40 \times$ objective using a Nikon Eclipse 80i microscope and exported as tiff files using Stereo Investigator software (MicroBrightField). The tiff files were imported into NIH ImageJ for analysis, and $200 \times 200$ pixel ROI was selected as described above. The smallest cell body in the ROI was manually chosen, and all objects with larger diameter than the selected cell body were excluded from the analysis to filter out signals from neuronal cell bodies and amyloid plaques. The remaining pixels correspond to the area covered by neurites. The area covered by neurites was automatically calculated for each ROI by MetaXpress. For PSD95 and silver staining quantification, four ROIs were randomly chosen for each analyzed section. Six CA1 hippocampal sections were analyzed from each mice, resulting in 24 ROIs for each mice. The data from all 24 ROIs were averaged for each mice. The obtained results from each of the six mice in vehicleand dantrolene-treated groups were averaged and presented as mean \pm SE $(n=6)$.

Statistical analysis. Statistical comparisons of results obtained in experiments were performed by one-way ANOVA test or Student's $t$ test. The $p$ values are indicated in the text and figure legends as appropriate. The differences between control and experimental groups were determined to be nonsignificant in cases in which $p>0.05$.

\section{Results}

Caffeine-induced $\mathrm{Ca}^{2+}$ release is enhanced in $3 \times \mathrm{TT}$ and $\mathrm{PS}$ DKO hippocampal neurons

Previous $\mathrm{Ca}^{2+}$ imaging studies indicated that RyanR-mediated $\mathrm{Ca}^{2+}$ release is enhanced in cortical and hippocampal neurons from 3xTg mice $\left(K I-P S 1_{M 146 V}\right.$, Thy1-APP $P_{K M 670 / 671 N L}$, Thy1- 
A

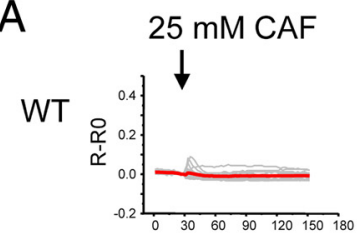

$3 \times \operatorname{Tg}$

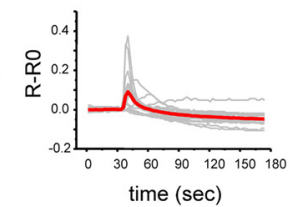

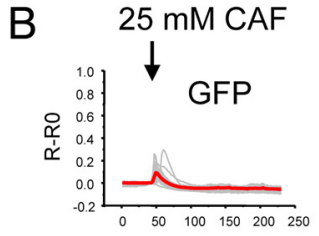
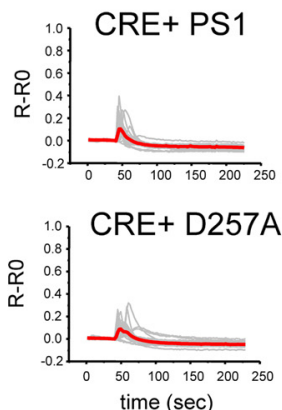
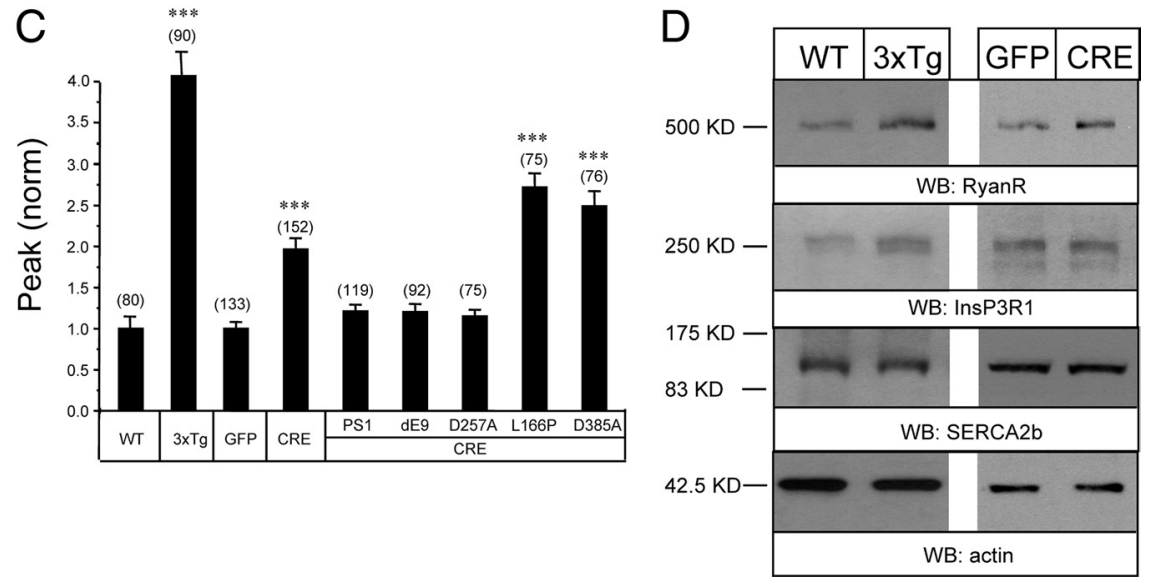

Figure 1. Caffeine-induced $\mathrm{Ca}^{2+}$ responses in $3 \times \mathrm{XT}$ and PS DKO hippocampal neurons. $\boldsymbol{A}, \boldsymbol{B}$, Fura- $2340 \mathrm{~nm} / 380 \mathrm{~nm}$ ratio traces are shown for WT and 3xTg hippocampal neurons ( $A$ ) and for PSCDKO hippocampal neurons infected with Lenti-GFP or Lenti-Cre viruses or lentiviral combinations (B). The neurons were challenged with $25 \mathrm{~mm}$ caffeine (CAF) as indicated. Individual cell traces (gray) and average traces (red) are shown for each group of neurons. $\boldsymbol{C}$, The peak values of caffeine-induced $\mathrm{Ca}^{2+}$ transients are shown for WT, 3XTg, and PSCDKO hippocampal neurons. In each experiment, the peak response was normalized to response in the WT group (for 3xTg experiments) or to the GFP-infected group (for PSCDK0 experiments). The normalized responses from different experiments were averaged and presented as mean \pm SE ( $n$ indicates number of cells analyzed). The peak responses in $3 x T g$ neurons were compared with peak responses in WT neurons, and the peak responses in PSCDKO neurons were compared with the GFP-infected group. ${ }^{* * *} p<0.001$. D, Lysates from WT and 3xTg hippocampal cultures were analyzed by Western blotting (WB) with antibodies against RyanR, InsP ${ }_{3} R 1$, and SERCA2b. Similar analysis was performed for PSCDKO hippocampal neurons infected with Lenti-GFP and Lenti-Cre viruses. Actin was used as a loading control. Representative blot is shown. Quantification of multiple blots is shown in supplemental Figure 2 (available at www.jneurosci.org as supplemental material).

$\operatorname{tau}_{P 301 L}$ ) and KI-PS1 $1_{M 146 V}$ mice (Guo et al., 1999; Chan et al., 2000; Smith et al., 2005; Stutzmann et al., 2006; Chakroborty et al., 2009). Consistent with these findings, we discovered that application of RyanR agonist caffeine resulted in much greater $\mathrm{Ca}^{2+}$ responses in postnatal hippocampal neuronal cultures from 3xTg mice than from the WT mice (Fig. 1A). On average, the peak amplitude of caffeine-induced $\mathrm{Ca}^{2+}$ responses was fourfold higher in 3xTg hippocampal neurons than in wild-type neurons (Fig. 1C). By reverse transcription-PCR analysis, we established that $A P P_{K M 670 / 671 N L}$ and tau P301L $_{L}$ transgenes (driven by Thyl promoter) are not expressed in these cultures before DIV18 (data not shown), and therefore observed differences in $\mathrm{Ca}^{2+}$ signals in DIV13 hippocampal neurons (Fig. $1 A$ ) are primarily attributable to $\mathrm{PS}_{\mathrm{M} 146 \mathrm{~V}}$ mutation. This is consistent with the previous comparison of $\mathrm{Ca}^{2+}$ signals in cortical neurons from KI-PS1 ${ }_{M 146 V}$ and 3xTg mice (Stutzmann et al., 2004, 2006; Smith et al., 2005). An increase in the RyanR expression levels has been
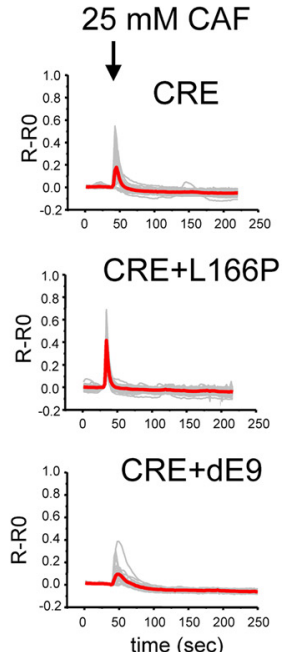

proposed to be responsible for the enhanced caffeine response in 3xTg and $\mathrm{KI}-$ $P S 1_{M 146 V}$ neurons (Chan et al., 2000; Smith et al., 2005; Stutzmann et al., 2006; Chakroborty et al., 2009). Western blot analysis of lysates prepared from DIV13 hippocampal cultures revealed a 1.8 -fold increase in RyanR expression levels in 3xTg cultures when compared with WT cultures (Fig. 1D) (supplemental Fig. 2, available at www.jneurosci.org as supplemental material). The levels of $\mathrm{InsP}_{3} \mathrm{R} 1$ were also increased in $3 \times \mathrm{Tg}$ cultures, although the difference with WT has not reach statistically significant levels (Fig. 1D) (supplemental Fig. 2, available at www.jneurosci.org as supplemental material). The SERCA2 $\mathrm{b} \mathrm{Ca}^{2+}$ pump was expressed at similar levels in 3xTg and WT neurons (Fig. 1D) (supplemental Fig. 2, available at www.jneurosci.org as supplemental material). Selective increase in neuronal RyanR expression levels is in agreement with previous studies with $3 \mathrm{xTg}$ and $\mathrm{KI}-\mathrm{PS} 1_{M 146 V}$ mice (Chan et al., 2000; Smith et al., 2005; Stutzmann et al., 2006; Chakroborty et al., 2009).

In the previous studies with MEFs, we discovered that presenilins function as ER $\mathrm{Ca}^{2+}$ leak channels and that disruption of $\mathrm{ER} \mathrm{Ca}^{2+}$ leak function of presenilins results in increased ER $\mathrm{Ca}^{2+}$ levels (Tu et al., 2006; Nelson et al., 2007, 2010). To determine whether presenilins function as ER $\mathrm{Ca}^{2+}$ leak channels in neurons, we established primary neuronal cultures from PScDKO mice ( $\left.P S 1^{d T A G / d T A G}, P S 2^{-/-}\right)$. In control rescue experiments with DKO MEF cells, we confirmed that the mouse dTAG-PS1 construct retains ER $\mathrm{Ca}^{2+}$ leak channel activity (data not shown). To generate PS DKO neurons, the PScDKO neurons were infected with lentiviruses encoding nuclear-targeted GFP-Cre fusion protein (NLS-Cre). In parallel control experiments, PScDKO cultures were infected with lentiviruses encoding nuclear-targeted GFP protein (NLS-GFP). The absence of PS2 in these cultures was confirmed by Western blotting of lysates with anti-PS2 mAb (data not shown). To determine the time course of PS1 disappearance in cortical PScDKO cultures infected with Lenti-Cre, the lysates for Western blotting experiments were prepared at variable time points after infection. From this analysis, we determined that the levels of full-length dTAG-PS1 are reduced below detection limit by DIV12 in these cultures (supplemental Fig. $1 B$, available at www.jneurosci.org as supplemental material). In contrast, levels of dTAG-PS1 remained unchanged in PScDKO cultures infected with control Lenti-GFP virus (supplemental Fig. $1 B$, available at www.jneurosci.org as supplemental material). Thus, we concluded that infection of PScDKO neurons with Lenti-Cre virus yielded PS DKO neurons. In $\mathrm{Ca}^{2+}$ imaging experiments, we discovered that application of caffeine induced significantly greater $\mathrm{Ca}^{2+}$ responses in PScDKO hippocampal neurons infected with 
Lenti-Cre viruses than in neurons infected with Lenti-GFP viruses (Fig. $1 B, C$ ). On average, the peak amplitude of caffeineinduced $\mathrm{Ca}^{2+}$ response was twofold larger in Cre-infected PScDKO hippocampal neurons than in GFP-infected PScDKO neurons (Fig. 1C). Western blot analysis revealed a trend toward increase in RyanR expression in Cre-infected PScDKO cultures, although the difference with GFP-infected cultures has not reached the level of statistical significance (Fig. 1D) (supplemental Fig. 2, available at www.jneurosci.org as supplemental material). The levels of InsP ${ }_{3} \mathrm{R} 1$ and SERCA2b were similar in both Cre-infected and GFP-infected PScDKO cultures (Fig. 1D) (supplemental Fig. 2, available at www.jneurosci.org as supplemental material).

We reasoned that enhanced caffeine responses in PS DKO cultures may be partially attributable to increased levels of RyanR expression (Fig. 1D) but may also be attributable to loss of ER $\mathrm{Ca}^{2+}$ leak function of presenilins and overloaded $\mathrm{ER} \mathrm{Ca}^{2+}$ stores. To determine an importance of $\mathrm{ER} \mathrm{Ca}^{2+}$ leak function of presenilins, we performed a series of rescue experiments. In these experiments, PScDKO neurons were coinfected with Lenti-Cre viruses and lentiviruses encoding HA-tagged human PS1 rescue constructs. As a result, endogenous mouse dTAG-PS1 protein in these neurons was deleted and replaced with overexpressed human HA-PS1 protein. We found that infection with wild-type Lenti-PS1 viruses reduced caffeine responses in PS DKO neurons to wild-type levels (Fig. $1 B, C$ ). In contrast, infection with PS1L166P FAD construct, which lost $\mathrm{Ca}^{2+}$ leak channel function (Nelson et al., 2007), did not reduce caffeine responses in PS DKO neurons (Fig. 1 B, C). Expression of PS1-L166P instead resulted in an additional increase in the size of caffeine-induced $\mathrm{Ca}^{2+}$ response (Fig. $1 \mathrm{~B}, C$ ), most likely caused by dominantnegative effects of this mutant on $\mathrm{ER} \mathrm{Ca}^{2+}$ leak activity of remaining endogenous PS1. Infection with PS1-D257A construct, which lost $\gamma$-secretase function but not $\mathrm{Ca}^{2+}$ leak channel function (Tu et al., 2006), rescued caffeine responses in PS DKO neurons (Fig. $1 B, C$ ). Infection with PS1-D385A construct, which lost both $\gamma$-secretase and $\mathrm{Ca}^{2+}$ leak channel functions $(\mathrm{O}$. Nelson and I. Bezprozvanny, unpublished observations), did not reduce the size of the caffeine response and actually increased it, similar to PS1-L166P FAD mutant (Fig. 1C). Infection with PS1$\triangle$ E9 FAD construct, which encodes a gain-of-function $\mathrm{ER} \mathrm{Ca}^{2+}$ leak mutant (Tu et al., 2006), rescued the size of the caffeine response in PS DKO neurons (Fig. $1 B, C$ ). Based on these results, we concluded that loss of $\mathrm{ER} \mathrm{Ca}^{2+}$ leak function and not $\gamma$-secretase function of presenilins resulted in increased caffeine responses in PS DKO neurons.

\section{$\mathrm{ER} \mathrm{Ca}^{2+}$ pool is increased and store-operated $\mathrm{Ca}^{2+}$ entry is reduced in 3xTg and PS DKO hippocampal neurons}

The increased responses to caffeine observed in $3 \times \mathrm{Tg}$ and PS DKO hippocampal neurons (Fig. $1 A-C$ ) could be due to increased levels of RyanR expression (Fig. 1D) (supplemental Fig. 2, available at www.jneurosci.org as supplemental material) or due to increased levels of ER $\mathrm{Ca}^{2+}$. To evaluate the ER $\mathrm{Ca}^{2+}$ content more directly, we measured the size of IO-sensitive $\mathrm{Ca}^{2+}$ pool in these neurons. Ionomycin is a $\mathrm{Ca}^{2+}$ ionophore that facilitates transport of $\mathrm{Ca}^{2+}$ across membranes. Addition of ionomycin induces exit of all ER-accumulated $\mathrm{Ca}^{2+}$ into the cytosol. The size of the IO-sensitive $\mathrm{Ca}^{2+}$ pool can be estimated by integrating a signal reported by cytosolic fura-2 after exposure to ionomycin. In the previous studies, we used a similar approach to evaluate ER $\mathrm{Ca}^{2+}$ content in wild-type and PS DKO MEF cells (Tu et al., 2006; Nelson et al., 2007). In experiments with hippocampal neurons, the cultures were transferred from aCSF (containing $2 \mathrm{mM} \mathrm{Ca}^{2+}$ ) to $\mathrm{Ca}^{2+}$-free media for $30 \mathrm{~s}$ and then challenged with $5 \mu \mathrm{M}$ ionomycin. An increase in the cytosolic fura-2 signal observed immediately after ionomycin addition was integrated and designated as $\mathrm{IO}_{30}$. We found that application of ionomycin resulted in significantly greater responses in $3 \mathrm{xTg}$ hippocampal cultures than in WT cultures (Fig. 2A). On average, the size of $\mathrm{IO}_{30} \mathrm{Ca}^{2+}$ pool was 2.7-fold greater in 3xTg neurons than in WT neurons (Fig. 2C).

We found that the IO-induced responses were also greater in PScDKO neurons infected with Lenti-Cre viruses than in neurons infected with Lenti-GFP viruses (Fig. $2 B$ ). On average, the size of the $\mathrm{IO}_{30} \mathrm{Ca}^{2+}$ pool was 1.7-fold greater in Cre-infected neurons (Fig. 2C). Coinfection with wild-type PS1 virus or with the virus expressing PS1-D257A “ $\gamma$-secretase mutant" rescued IO-induced responses back to the levels observed in GFPinfected cultures (Fig. $2 \mathrm{~B}, \mathrm{C}$ ). In contrast, coinfection with "loss of ER $\mathrm{Ca}^{2+}$ leak" function FAD mutant PS1-L166P did not rescue $\mathrm{IO}$ responses and instead resulted in enhanced responses (Fig. $2 \mathrm{~B}$ ). On average, the size of the $\mathrm{IO}_{30} \mathrm{Ca}^{2+}$ pool was threefold greater in PScDKO neurons coinfected with Cre and PS1L166P viruses than in PScDKO neurons infected with GFP viruses (Fig. $2 C$ ). Similar results were observed in experiments with PS1-D385A mutant, which lost both $\gamma$-secretase and ER $\mathrm{Ca}^{2+}$ leak functions (Fig. 2C). As discussed above, it is likely that PS1-L166P and PS1-D385A mutants exert a dominant-negative effect on $\mathrm{ER} \mathrm{Ca}^{2+}$ leak activity of endogenous PS1 still remaining in Cre-infected PScDKO neurons. Coinfection of Lenti-Cre with the "gain of $\mathrm{Ca}^{2+}$ leak function" PS1- $\Delta \mathrm{E} 9 \mathrm{FAD}$ mutant reduced the size of IO responses to the levels even below levels observed in GFP-infected PScDKO neurons, consistent with superleaky ER membrane (Fig. $2 \mathrm{~B}, \mathrm{C}$ ). Based on these results, we concluded that loss of $\mathrm{ER} \mathrm{Ca}^{2+}$ leak function and not $\gamma$-secretase function of presenilins resulted in the increased size of IO-sensitive $\mathrm{Ca}^{2+}$ pool in PS DKO neurons.

Ionomycin is a $\mathrm{Ca}^{2+}$ ionophore that, in our experiments, facilitates $\mathrm{Ca}^{2+}$ transport across all intracellular membranes and not only across ER membranes. Thus, some of the $\mathrm{Ca}^{2+}$ in the IO-sensitive $\mathrm{Ca}^{2+}$ pool may come from other intracellular compartments, such as Golgi apparatus or mitochondria. To confirm the results obtained with ionomycin, we took advantage of the recently developed ER-targeted genetic $\mathrm{Ca}^{2+}$ indicator D1ER (Palmer et al., 2004; McCombs and Palmer, 2008). D1ER is a FRET-based cameleon $\mathrm{Ca}^{2+}$ indicator composed of ECFP and citrin fluorescent proteins separated by a linker encoding CaM and CaM-binding M13 peptide sequence (Fig. $3 A$ ). During $\mathrm{Ca}^{2+}$ binding to CaM, CaM binds to M13 target sequence and brings ECFP and citrin proteins in close proximity, which facilitates FRET between these proteins (Fig. 3A). CRT targeting sequence was added to the $\mathrm{N}$ terminus, and $\mathrm{ER}$ retention sequence was added to the $\mathrm{C}$ terminus of D1ER protein to facilitate ER targeting and retention (Fig. 3A) (Palmer et al., 2004). To validate utility of D1ER indicator for our experiments, we transiently transfected the D1ER plasmid to wild-type and PS DKO MEF cells. Consistent with previous results obtained using MagFura-2 ER Ca ${ }^{2+}$ indicator (Tu et al., 2006), we discovered that ER $\mathrm{Ca}^{2+}$ levels reported by D1ER are several fold higher in PS DKO MEF cells when compared with wild-type cells (data not shown). In experiments with neurons, D1ER expression plasmid was transiently transfected to WT and 3xTg hippocampal neuronal cultures. Proper targeting of D1ER construct to neuronal ER compartment was confirmed in immunostaining experiments with polyclonal anti-CRT antibodies (Fig. 3B). To minimize effects of cell-to-cell variability in D1ER expression levels, we normalized FRET signal from D1ER indicator to CFP signal 
A

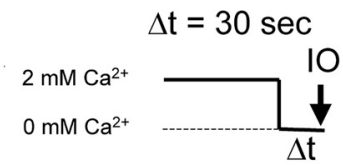

B

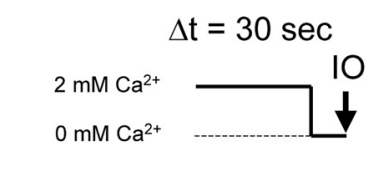

WT
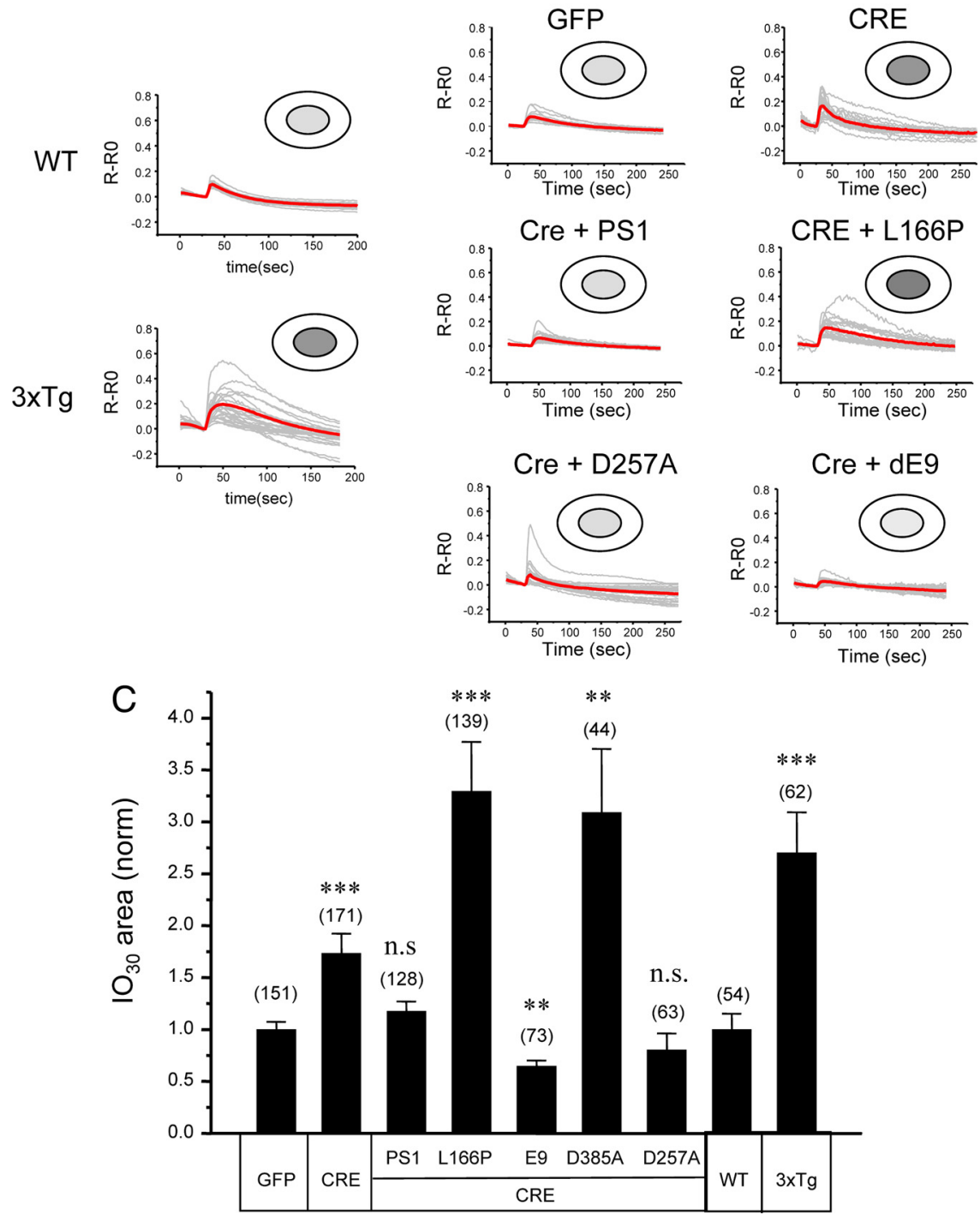

Figure 2. Ionomycin-sensitive $\mathrm{Ca}^{2+}$ pool in $3 \times \mathrm{xTg}$ and PS DKO hippocampal neurons. $\boldsymbol{A}, \boldsymbol{B}$, Fura- $2340 \mathrm{~nm} / 380 \mathrm{~nm}$ ratio traces are shown for WT and 3xTg hippocampal neurons $(\boldsymbol{A})$ and for PSCDKO hippocampal neurons infected with Lenti-GFP or Lenti-Cre viruses or lentiviral combinations $(\boldsymbol{B})$. The neurons were moved to $\mathrm{Ca}^{2+}$-free media for $30 \mathrm{~s}$ and challenged with $5 \mu \mathrm{M} \mathrm{I0}$. Individual cell traces (gray) and average traces (red) are shown for each group of neurons. $\boldsymbol{C}$, The average size of ionomycinsensitive $\mathrm{Ca}^{2+}$ pool after $30 \mathrm{~s}$ incubation in $\mathrm{Ca}^{2+}$ free media $\left(\mathrm{IO}_{30}\right)$. The area under 10 -induced fura- 2 signal was integrated for each neuron. In each experiment, $\mathrm{IO}_{30}$ values were normalized to $\mathrm{IO}_{30}$ values measured for the WT group (for $3 \mathrm{xTg}$ experiments) or to the GFP-infected group (for PSCDKO experiments). The normalized responses from different experiments were averaged and presented as mean $\pm \mathrm{SE}$ ( $n$ indicates number of cells analyzed). The $\mathrm{IO}_{30}$ values in $3 \mathrm{xTg}$ neurons were compared with $\mathrm{IO}_{30}$ values in WT neurons, and the $10_{30}$ values in PSCDKO neurons were compared with $10_{30}$ values in the GFP-infected group. ${ }^{* *} p<0.01$; ${ }^{* * *} p<0.001$. n.s., Not significant.

observed for the same cell. When cultured in aCSF media containing $2 \mathrm{mM} \mathrm{Ca}^{2+}$, $3 \times \mathrm{Tg}$ neurons had a significantly higher FRET/CFP ratio than WT neurons, consistent with elevated $\mathrm{ER} \mathrm{Ca}^{2+}$ concentration (Fig. $3 C$ ). After transfer to $\mathrm{Ca}^{2+}$-free aCSF media and addition of $2 \mu \mathrm{M}$ of the SERCA pump inhibitor thapsigargin, FRET/CFP ratios were reduced in both WT and $3 \times \mathrm{xTg}$ neurons, indicating store depletion caused by $\mathrm{ER} \mathrm{Ca}^{2+}$ leak activity. In WT cells, FRET/CFP ratios were reduced to basal levels within $75 \mathrm{~s}$ after addition of thapsigargin (Fig. $3 C$ ). In contrast, it took at least $250 \mathrm{~s}$ for FRET/CFP ratios to reduce to a new basal state in 3xTg neurons, consistent with impaired $\mathrm{ER} \mathrm{Ca}^{2+}$ leak function (Fig. 3C). Also, basal FRET/CFP ratios after thapsigargin application were significantly higher in $3 \times$ Tg neurons than in WT neurons (Fig. 3C). Addition of $5 \mu \mathrm{M}$ ionomycin had no addition effect on FRET/ CFP in WT neurons but caused addition reduction of FRET/CFP ratios in $3 \times \mathrm{Tg}$ neurons to the same levels as observed in WT neurons (Fig. 3C). From these experiments, we concluded that, in $3 x \mathrm{Tg}$ neurons, a significant portion of $\mathrm{Ca}^{2+}$ is accumulated in the thapsigargininsensitive ER pool. This pool was not observed in our experiments with WT neurons, in which all $\mathrm{ER} \mathrm{Ca}^{2+}$ could be released by thapsigargin (Fig. $3 C$ ). Thus, appearance of this new pool is likely to be a result of compensation to impaired ER $\mathrm{Ca}^{2+}$ leak function in $3 \times \mathrm{TT}$ neurons. Addition studies will be required to identify the nature of this ER subcompartment. Another possibility is that the rate of ER $\mathrm{Ca}^{2+}$ leak was so reduced in $3 x \mathrm{Tg}$ neurons that $600 \mathrm{~s}$ incubation with thapsigargin was insufficient to deplete the stores completely. To convert FRET/CFP ratios to absolute $\mathrm{ER} \mathrm{Ca}^{2+}$ values, we concluded each experiment with a calibration procedure using a series of extracellular solutions with defined $\mathrm{Ca}^{2+}$ concentrations. As a result of this procedure, calibration D1ER curves were constructed for WT and 3xTg neurons (supplemental Fig. 3, available at www.jneurosci.org as supplemental material). Using these calibration curves, we estimated that, in the basal state, the $\mathrm{ER} \mathrm{Ca}^{2+}$ levels were equal to $207 \pm 47 \mu \mathrm{M}(n=100)$ in WT hippocampal neurons and $623 \pm 108 \mu \mathrm{M}(n=51)$ in $3 \times$ Tg neurons $(p<0.001)$. The threefold increase in $\mathrm{ER} \mathrm{Ca}^{2+}$ levels in 3xTg neurons reported by D1ER indicator is in near perfect agreement with a 2.5 -fold increase in the size of the IO-sensitive $\mathrm{Ca}^{2+}$ pool that we measured for the same neurons using fura-2 (Fig. $2 A, C$ ). Thus, in future experiments, we focused on IOsensitive $\mathrm{Ca}^{2+}$ pool measurements because of the relative simplicity of experimental procedures involved in these measurements.

The filling state of $\mathrm{ER} \mathrm{Ca}^{2+}$ pool regulates the store-operated $\mathrm{Ca}^{2+}$ entry (SOC) pathway (Venkatachalam et al., 2002). To investigate effects of presenilin deletions and mutations on activation of the neuronal SOC pathway, we transferred fura-2loaded hippocampal neurons from aCSF media to $\mathrm{Ca}^{2+}$-free media for $2 \mathrm{~min}$ and then returned neurons to aCSF media. The $\mathrm{ER} \mathrm{Ca}^{2+}$ pool is depleted during incubation in $\mathrm{Ca}^{2+}$-free media, and " $\mathrm{Ca}^{2+}$ readdition" results in activation of SOC-mediated $\mathrm{Ca}^{2+}$ entry. We found that PScDKO neurons infected with LentiGFP respond to $\mathrm{Ca}^{2+}$ readdition more strongly than PScDKO 
A

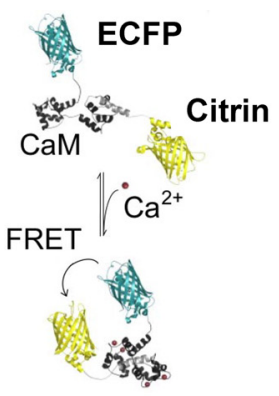

CRT

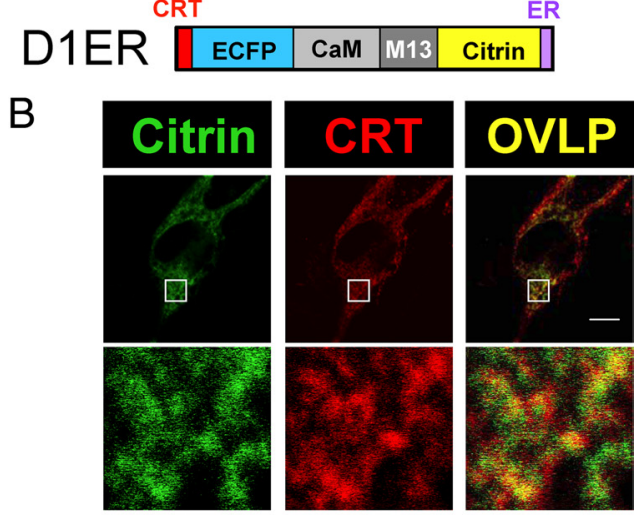

C

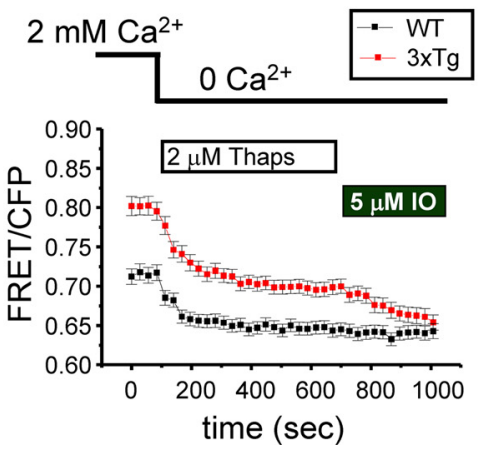

Figure 3. $E \mathrm{Ca}^{2+}$ concentration is elevated in 3xTg hippocampal neurons. A, Principle of D1ER indicator (adapted from McCombs and Palmer, 2008). D1ER is a FRET-based cameleon $\mathrm{Ca}^{2+}$ indicator composed of ECFP (structure shown in cyan) and citrin fluorescent protein (structure shown in yellow) separated by a linker encoding CaM and CaM-binding M13 peptide sequence. CRT targeting sequence is added to the $\mathrm{N}$ terminus and the ER retension sequence is added to $C$ terminus of D1ER protein to facilitate ER targeting and retension. $\boldsymbol{B}, \mathrm{D}$ 1ER is targeted to ER in hippocampal neurons. Hippocampal neurons were transiently transfected with D1ER plasmid, fixed, permeabilized, and stained with polyclonal antibodies against CRT. Subcellular localization of D1ER was determined by imaging on citrin channel (left, green). The location of CRT was visualized by rhodamine-conjugated secondary anti-rabbit antibodies (middle, red). The overlap between D1ER and CRT signals is shown on the right (OVLP) as yellow. Scale bar, 5 $\mu \mathrm{m}$. The $10 \times$ magnified region is shown as indicated. C, D1ER signals from WT and 3xTg neurons. The FRET/CFP signal ratios for neurons transfected with D1ER plasmid are shown as a function of time as mean \pm SE ( $n=100$ for WT cells and 51 for $3 \times$ Tg cells) for WT neurons (black squares) and $3 \times \operatorname{Tg}$ neurons (red squares). The time of change to $\mathrm{Ca}^{2+}$-free aCSF and times of addition of $2 \mu \mathrm{m}$ thapsigargin (Thaps) and $5 \mu \mathrm{m} 10$ are as indicated.

neurons infected with Lenti-Cre (Fig. 4A). We also discovered that $\mathrm{Ca}^{2+}$ readdition results in much stronger responses in WT hippocampal neurons than in 3xTg neurons (Fig. 4B). On average, the size of the peak $\mathrm{Ca}^{2+}$ response was reduced twofold in Cre-infected PScDKO neurons and in 3xTg neurons when compared with control groups (Fig. 4C). Our results (Fig. 4) are in agreement with previous studies of SOC in PS FAD mutant cells (Leissring et al., 2000; Yoo et al., 2000; Herms et al., 2003; Akbari et al., 2004), but our conclusion is that presenilins affect SOC in
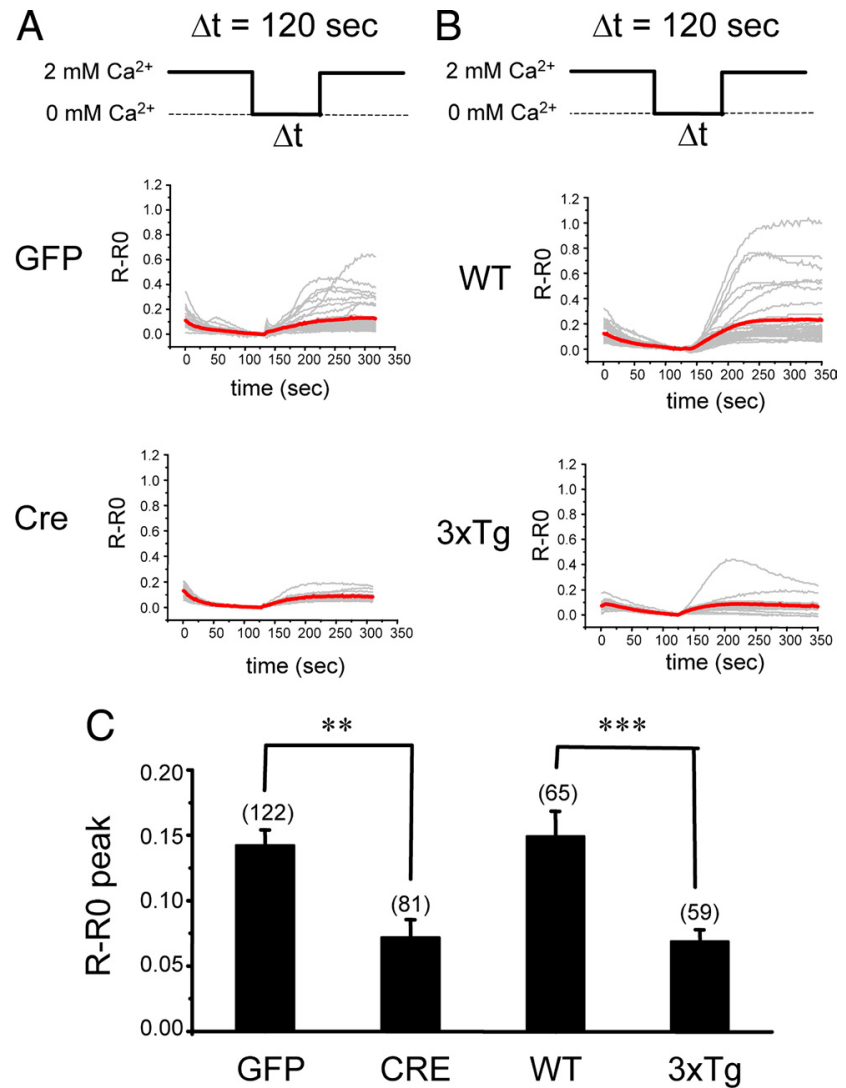

Figure 4. Store-operated $\mathrm{Ca}^{2+}$ entry in $3 \times \mathrm{XT}$ and PS DKO hippocampal neurons. $A, B$, Fura-2 $340 \mathrm{~nm} / 380 \mathrm{~nm}$ ratio traces are shown for PSCDKO hippocampal neurons infected with LentiGFP or Lenti-Cre viruses $(\boldsymbol{A})$ and WT or $3 \times \mathrm{Xg}$ hippocampal neurons $(\boldsymbol{B})$. The neurons were moved from aCSF to $\mathrm{Ca}^{2+}$-free media for $120 \mathrm{~s}$ and then returned to aCSF. Individual cell traces (gray) and average traces (red) are shown for each group of neurons. $C$, An average fura-2 peak responses to $\mathrm{Ca}^{2+}$ readdition are shown for PSCDKO neurons infected with Lent-GFP or LentiCre and for WT or 3XTg neurons. The average peak SOC responses are shown as mean \pm SE ( $n$ indicates number of cells analyzed in each group). ${ }^{* *} p<0.01 ;{ }^{* * *} p<0.001$.

hippocampal neurons indirectly, by controlling the filling state of $\mathrm{ER} \mathrm{Ca}^{2+}$ stores. A similar hypothesis has been proposed previously based on the analysis of SOC in KI-PS1 $1_{M 146 V}$ fibroblasts (Leissring et al., 2000).

\section{$\mathrm{ER} \mathrm{Ca}^{2+}$ leak is impaired in 3xTg and PS DKO \\ hippocampal neurons}

The results obtained from $\mathrm{IO}_{30}$ and D1ER measurements (Figs. 2 and 3) are consistent with the hypothesis that the $\mathrm{ER} \mathrm{Ca}^{2+}$ leak pathway is impaired in $3 \times \mathrm{Tg}$ and PS DKO hippocampal neurons. To measure the rate of passive $\mathrm{ER} \mathrm{Ca}^{2+}$ leak in these neurons more directly, we compared the sizes of IO-induced $\mathrm{Ca}^{2+}$ responses after 30 and $120 \mathrm{~s}$ incubation in $\mathrm{Ca}^{2+}$-free media. We used the $\mathrm{IO}_{120} / \mathrm{IO}_{30}$ ratio as a quantitative measure of passive $\mathrm{Ca}^{2+}$ loss from the ER within $90 \mathrm{~s}$ time period attributable to endogenous $\mathrm{ER} \mathrm{Ca}^{2+}$ leak pathway activity. Because the size of $\mathrm{IO}_{30}$ pool is very small in WT neurons and in PScDKO neurons infected with Lenti-GFP (Fig. 2), in these experiments, we refilled the stores with $\mathrm{Ca}^{2+}$ by $1 \mathrm{~min}$ exposure to $15 \mathrm{~mm} \mathrm{KCl}$ in aCSF. Resulting depolarization induces opening of voltage-gated $\mathrm{Ca}^{2+}$ channels and rapid $\mathrm{Ca}^{2+}$ influx into the hippocampal neurons, which leads to filling of the $\mathrm{ER} \mathrm{Ca}^{2+}$ stores. We did not see much difference in $\mathrm{KCl}$-induced $\mathrm{Ca}^{2+}$ responses between different groups of cells (data not shown). Immediately after $\mathrm{KCl}$ depolarization, the neurons were transferred to $\mathrm{Ca}^{2+}$-free media for $30 \mathrm{~s}$ 
A

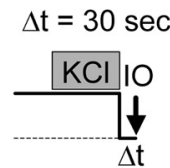

GFP
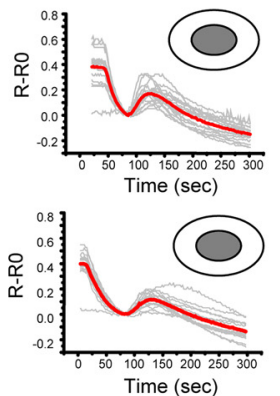

B
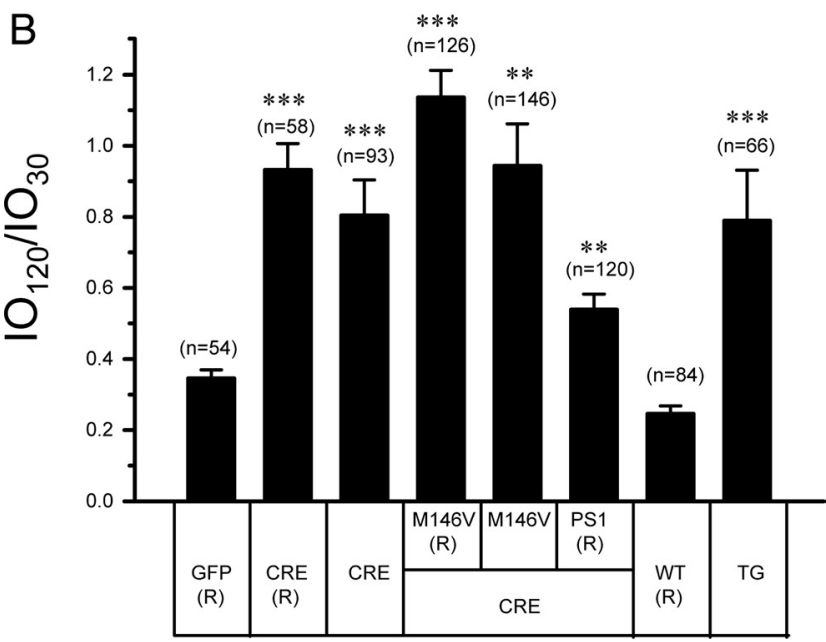

Figure 5. The ER $\mathrm{Ca}^{2+}$ leak measurements in 3xTg and PS DKO hippocampal neurons. $A$, Fura- $2340 \mathrm{~nm} / 380 \mathrm{~nm}$ ratio traces are shown for PSCDKO hippocampal neurons infected with Lenti-GFP or Lenti-Cre viruses. The neurons were stimulated with $15 \mathrm{~mm} \mathrm{KCl}$ for $1 \mathrm{~min}$ in aCSF and then moved to $\mathrm{Ca}^{2+}$-free media for 30 or 120 s and challenged with $5 \mu \mathrm{m}$ I0. Individual cell traces (gray) and average traces (red) are shown for each group of neurons. $\boldsymbol{B}$, The average ER $\mathrm{Ca}^{2+}$ residual pool is shown as the $10_{120} / \mathrm{IO}_{30}$ ratio. In each experiment, $\mathrm{IO}_{30}$ and $\mathrm{IO}_{120}$ values were measured, and the $10_{120} / \mathrm{IO}_{30}$ ratio was determined for each batch of neurons. The $10_{120} \mathrm{I}$ $1 \mathrm{O}_{30}$ ratios from different experiments were averaged and presented as mean $\pm \mathrm{SE}$ ( $n$ indicates number of cells analyzed). The experiments that included the $15 \mathrm{~mm} \mathrm{KCl}$ refill protocol are indicated with "(R)." The $10_{120} / \mathrm{IO}_{30}$ ratio in 3xTg neurons was compared with the $10_{120} / \mathrm{IO}_{30}$ ratio in the WT(R) group of neurons. The $10_{120} / 10_{30}$ ratios in PSCDKO neurons were compared with the $10_{120} / 10_{30}$ ratio in the GFP(R) group. ${ }^{* *} p<0.01 ;{ }^{* * *} p<0.001$.

and challenged with ionomycin. Application of ionomycin in these conditions resulted in similar responses in PScDKO hippocampal neurons infected with Lenti-GFP and Lenti-Cre viruses (Fig. 5A), indicating that the stores were completely full in both cultures. When length of incubation in $\mathrm{Ca}^{2+}$-free media was extended to $120 \mathrm{~s}$, ionomycin induced significantly smaller responses in PScDKO neurons infected with Lenti-GFP than in neurons infected with Lenti-Cre (Fig. $5 \mathrm{~A}$ ). On average, the $\mathrm{IO}_{120} /$ $\mathrm{IO}_{30}$ ratio was equal to 0.35 for GFP-infected PScDKO neurons and 0.93 for Cre-infected PScDKO neurons (Fig. 5B). We interpreted these results as an indication that PScDKO neurons infected with Lenti-GFP lost $65 \%$ of accumulated $\mathrm{ER} \mathrm{Ca}^{2+}$ after $90 \mathrm{~s}$ incubation in $\mathrm{Ca}^{2+}$-free media. In contrast, PScDKO neurons infected with Lenti-Cre only lost 7\% of accumulated ER $\mathrm{Ca}^{2+}$ during the same time period. Thus, the ER membrane in GFP-infected PScDKO neurons is much more leaky for $\mathrm{Ca}^{2+}$ than the ER membrane in Cre-infected PScDKO hippocampal neurons. This conclusion did not depend on using the $\mathrm{KCl}$ refill protocol, because the $\mathrm{IO}_{120} / \mathrm{IO}_{30}$ ratio was equal to 0.8 for PScDKO neurons infected with Lenti-Cre in the absence of $\mathrm{KCl}$ refill step (Fig. $5 B$ ). The $\mathrm{IO}_{120} / \mathrm{IO}_{30}$ ratio could not be measured for PScDKO neurons infected with Lenti-GFP in the absence of $\mathrm{KCl}$ refill as $\mathrm{IO}_{30}$ pool was too small for these neurons (Fig. 2). Coinfection of Cre with the wild-type PS1 virus resulted in partial rescue of the leak function, yielding a $\mathrm{IO}_{120} / \mathrm{IO}_{30}$ ratio of 0.5 after $\mathrm{KCl}$ refill (Fig. $5 B$ ). In contrast, coinfection of Cre virus with the mutant PS1-M146V virus did not rescue the leak function, yielding a $\mathrm{IO}_{120} / \mathrm{IO}_{30}$ ratio of 1.15 after $\mathrm{KCl}$ refill and 0.95 in the absence of $\mathrm{KCl}$ refill (Fig. $5 B$ ). A similar paradigm was applied to compare $\mathrm{ER} \mathrm{Ca}^{2+}$ leak in WT and 3xTg neurons. We found that the $\mathrm{IO}_{120} / \mathrm{IO}_{30}$ ratio was equal to 0.25 in WT neurons after the $\mathrm{KCl}$ refill protocol and 0.79 in $3 \times \mathrm{TTg}$ neurons (Fig. 5B). Thus, within 90 s incubation in $\mathrm{Ca}^{2+}$-free media, WT neurons lost $75 \%$ of accumulated $\mathrm{Ca}^{2+}$ and $3 \times \mathrm{Tg}$ neurons only lost $21 \%$. The $\mathrm{IO}_{120} / \mathrm{IO}_{30}$ ratio could not be measured in WT neurons without $\mathrm{KCl}$ refill because the size of the $\mathrm{IO}_{30} \mathrm{Ca}^{2+}$ pool is too small in these neurons (Fig. 2). From these results, we concluded that ER $\mathrm{Ca}^{2+}$ leak function is impaired in $3 \mathrm{xTg}$ and PS DKO neurons. We further concluded that $\mathrm{ER} \mathrm{Ca}^{2+}$ leak function in PS DKO neurons can be rescued by expression of wild-type PS1 but not PS1M146V mutant.

\section{$\mathrm{ER} \mathrm{Ca}^{2+}$ leak function in $3 \mathrm{xTg}$ and PS DKO medium spiny striatal neurons}

$\mathrm{AD}$ preferentially affects hippocampal and cortical neurons, whereas other neuronal populations are not affected (Gomez-Isla et al., 2008). The reasons for the selective vulnerability of hippocampal and cortical neurons in $\mathrm{AD}$ are not well understood. Although the role of $\mathrm{ER} \mathrm{Ca}^{2+}$ leak function of presenilins in $\mathrm{AD}$ pathogenesis is not yet clear, we reasoned that it may be of interest to evaluate $\mathrm{ER} \mathrm{Ca}^{2+}$ leak function of presenilins in vulnerable and resistant neuronal populations. In experiments described above, we demonstrated that $\mathrm{ER} \mathrm{Ca}^{2+}$ stores in hippocampal neurons are very leaky and that FAD mutations or genetic deletion of presenilins dramatically impair $\mathrm{ER} \mathrm{Ca}^{2+}$ leak function in these neurons (Figs. 2, 5). For the next series of experiments, we focused on striatal medium spiny neurons (MSNs), which are selectively affected in Huntington's disease (Vonsattel and DiFiglia, 1998) but essentially spared in AD (Gomez-Isla et al., 2008). The MSN PScDKO neuronal cultures were established and infected with Lenti-GFP and Lenti-Cre viruses as described above for hippocampal neurons. Similar to procedures used for hippocampal neurons, MSNs were transferred from aCSF media to $\mathrm{Ca}^{2+}$-free media for 30 or $120 \mathrm{~s}$ and challenged with ionomycin. In contrast to hippocampal neurons, we found that PScDKO MSNs infected with Lenti-GFP respond strongly to ionomycin after 30 and $120 \mathrm{~s}$ incubation in $\mathrm{Ca}^{2+}$-free media (Fig. 6A). On average, the $\mathrm{IO}_{120} / \mathrm{IO}_{30}$ ratio was equal to 0.75 for PScDKO MSNs infected with Lenti-GFP (Fig. 6C). The PScDKO MSNs infected with Lenti-Cre virus also responded strongly to ionomycin after 30 and $120 \mathrm{~s}$ incubation in $\mathrm{Ca}^{2+}$-free media (Fig. 6A). The average $\mathrm{IO}_{120} / \mathrm{IO}_{30}$ ratio for these neurons was equal to 1.2 (Fig. $6 \mathrm{C}$ ). Similar to PScDKO MSNs, we found that both WT and 3xTg MSNs responded strongly to ionomycin after 30 and $120 \mathrm{~s}$ in $\mathrm{Ca}^{2+}$-free media (Fig. $6 \mathrm{~B}$ ). On average, the $\mathrm{IO}_{120} / \mathrm{IO}_{30}$ ratio was equal to 0.5 for WT neurons and 1.05 for 3xTg neurons (Fig. 6C). From these results, we concluded that presenilins play a role as ER $\mathrm{Ca}^{2+}$ leak channels in MSNs, but the ER $\mathrm{Ca}^{2+}$ leak activity is much less potent in MSNs than in hippocampal neurons. 
To explain the differences between MSNs and hippocampal neurons, we evaluated expression of full-length PS1 in lysates prepared from hippocampal and MSN PScDKO neurons infected with Lenti-GFP and Lenti-Cre viruses. Actin was used as a loading control in these experiments (Fig. 6D). The monoclonal anti-FLAG antibodies were used in these experiments for PS1 detection by taking an advantage of the dTAG epitope inserted into the PS1 N-terminal locus. Consistent with the previous studies (Annaert et al., 1999), we detected both full-length and cleaved forms of PS1 in lysates prepared from GFP-infected PScDKO hippocampal neurons and MSNs (Fig. 6D). As expected, in both types of neurons, the cleaved PS1 form (PS1-NTF and PS1-CTF) was significantly more abundant than the holoprotein form (Fig. 5D). Infection with Lenti-Cre resulted in complete loss of holoprotein and PS1-CTF forms and major reduction in the PS1-NTF form in both neuronal populations (Fig. 6D). As we reported previously, only holoprotein presenilins support ER $\mathrm{Ca}^{2+}$ leak activity (Tu et al., 2006). It is of interest that the PS1 holoprotein was less abundant in MSN neuronal lysates than in hippocampal neuronal lysates (Fig. 6D). Thus, it is possible that reduced ER $\mathrm{Ca}^{2+}$ leak activity in MSNs is related to comparatively lower levels of PS1 holoprotein expressed in these neurons.

\section{Ryanodine receptors and $\mathrm{ER} \mathrm{Ca}^{2+}$ leak in hippocampal neurons}

Western blot analysis revealed a significant increase in RyanR expression levels in 3xTg hippocampal neurons (Fig. 1D) (supplemental Fig. 2, available at www.jneurosci.org as supplemental material). There was also a trend toward an increase in RyanR expression levels in PS DKO hippocampal neurons (Fig. 1D) (supplemental Fig. 2, available at www.jneurosci.org as supplemental material). The effect on RyanR expression was specific, because expression of Ins $\mathrm{P}_{3} \mathrm{R} 1$ in the same cultures was affected much less than expression of RyanR and expression of SERCA2b was not affected (Fig. 1D) (supplemental Fig. 2, available at www.jneurosci.org as supplemental material). We hypothesized that an increase in RyanR expression may be a compensatory response to impaired ER $\mathrm{Ca}^{2+}$ leak function in these neurons. To test this hypothesis, we cultured WT and 3xTg hippocampal neurons for $6 \mathrm{~d}$ (DIV7DIV13) in the presence of $50 \mathrm{~nm}$ dantrolene, a membranepermeable RyanR inhibitor (Krause et al., 2004). After exposure to dantrolene, neurons were moved from aCSF to $\mathrm{Ca}^{2+}$-free media for $30 \mathrm{~s}$ and stimulated with ionomycin. We found that incubation with dantrolene had only minor effects on IO-induced responses in WT neurons (Fig. 7A). Although some upward trend was observed, on average the size of the $\mathrm{IO}_{30} \mathrm{Ca}^{2+}$ pool was not significantly different between control and dantrolene-exposed groups of WT hippocampal neurons (Fig. 7B). In contrast, incu- bation with dantrolene dramatically enhanced $\mathrm{IO}$-induced $\mathrm{Ca}^{2+}$ responses in 3xTg cells (Fig. 7A). On average, the $\mathrm{IO}_{30} \mathrm{Ca}^{2+}$ pool size was twofold larger in $3 \mathrm{xTg}$ hippocampal neurons exposed to dantrolene than in the control group of 3xTg neurons and eightfold larger than in the control group of WT neurons (Fig. $7 B$ ). Consistent with the previous findings (Fig. $2 \mathrm{~A}, \mathrm{C}$ ), the $\mathrm{IO}_{30} \mathrm{Ca}^{2+}$ pool size was fourfold larger in the control group of $3 \times \mathrm{xT}$ neurons than in control group of WT neurons (Fig. 7B).

Dantrolene is relatively specific for RyanR (Krause et al., 2004) but also inhibits other targets such as channels involved in storeoperated $\mathrm{Ca}^{2+}$ entry (Zhao et al., 2006). To test the role of RyanR more specifically, we infected WT and 3xTg neuronal cultures with lentiviruses encoding shRNAi against RyanR (RyR-shRNAi) or control shRNAi (Ctrl-shRNAi). RyR-shRNAi is directed against mouse RyanR1 sequence, but, in control quantitative PCR experiments, we discovered that infection with RyR-shRNAi lentiviruses also reduced expression of RyanR2 and RyanR3 in hippocampal neurons (data not shown). An efficient knockdown of RyanRs in 3xTg hippocampal neurons infected with RyR-shRNAi was confirmed in control Western blotting experiments with pan-RyanR antibodies (supplemental Fig. 4, available at www.jneurosci.org as supplemental material). We found that $\mathrm{IO}$-induced $\mathrm{Ca}^{2+}$ re- 
A

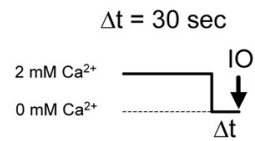

WT
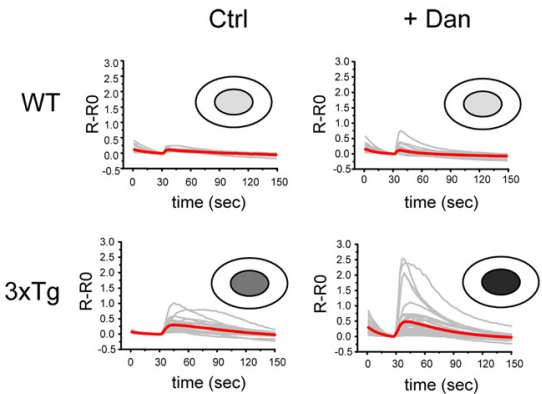

B

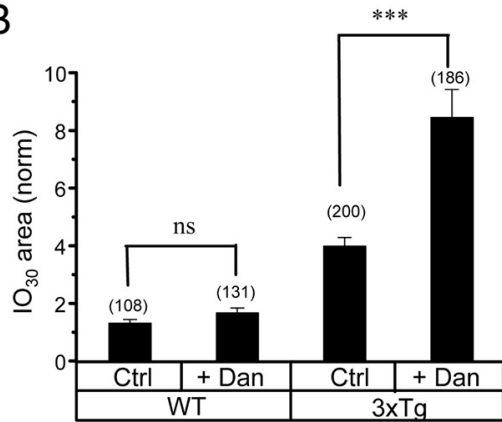

C
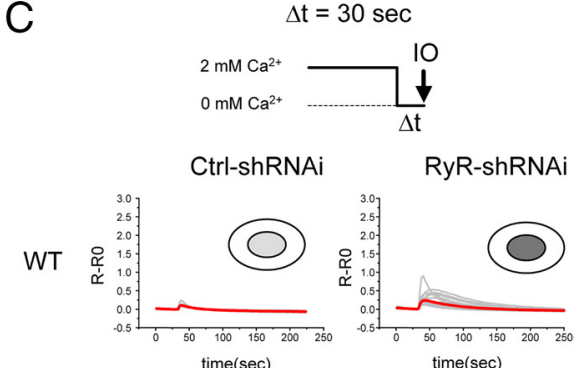

$3 \times \operatorname{Tg}$
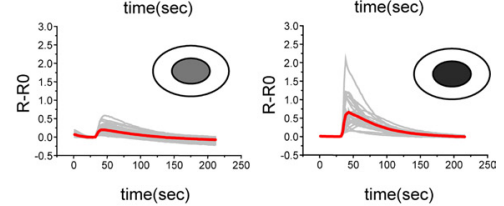

time(sec)

$\mathrm{D}$

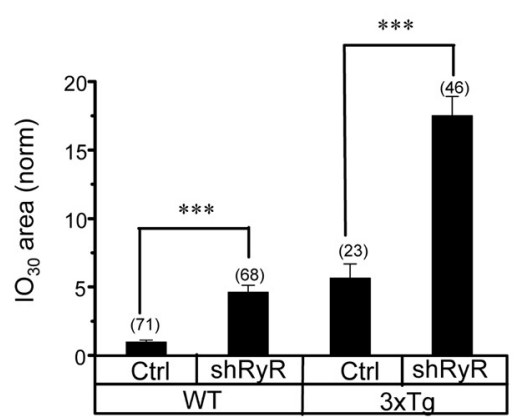

Figure 7. RyanRs compensate for impaired ER Ca ${ }^{2+}$ leak function in 3xTg hippocampal neurons. A, C, Fura- $2340 \mathrm{~nm} / 380 \mathrm{~nm}$ ratio traces are shown for WT and 3xTg hippocampal neurons in control conditions (Ctrl) or after preincubation with $50 \mathrm{~nm}$ dantrolene (Dan) (A) and for WT and 3xTg hippocampal neurons infected with control shRNAi lentivirus (Ctrl) or RyanR-targeted shRNAi lentivirus (RyR) (C). The neurons were moved to $\mathrm{Ca}^{2+}$-free media for $30 \mathrm{~s}$ and challenged with $5 \mu \mathrm{m} 10$. Individual cell traces (gray) and average cell traces (red) are shown for each group of neurons. $\boldsymbol{B}, \boldsymbol{D}$, The average size of the ionomycin-sensitive $\mathrm{Ca}^{2+}$ pool after $30 \mathrm{~s}$ incubation in $\mathrm{Ca}^{2+}$-free media $\left(\mathrm{IO}_{30}\right)$. The area under 10 -induced fura-2 signal was integrated for each neuron. In each experiment, $10_{30}$ values were normalized to $\mathrm{IO}_{30}$ values measured for the WT Ctrl group. The normalized responses from different experiments were averaged and presented as mean $\pm S E$ ( $n$ indicates number of cells analyzed). ${ }^{* *} p<0.001$. ns, Not significant.
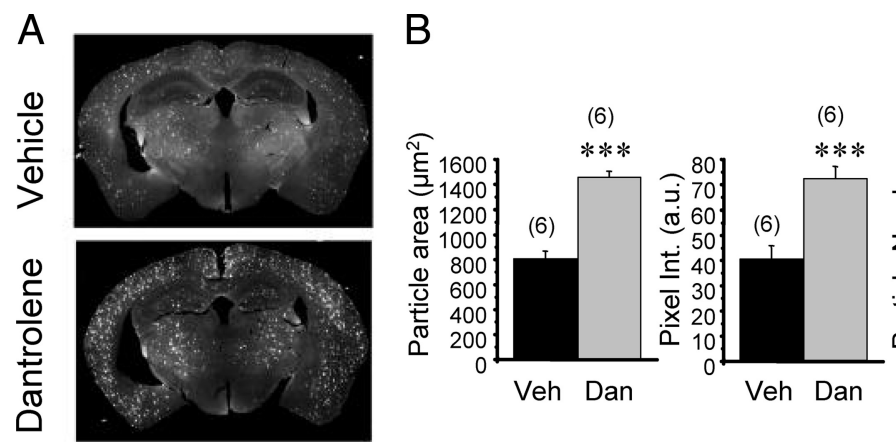

Figure 8. Long-term dantrolene feeding increases amyloid accumulation in brains of APPPS1 mice. $A$, The coronal sections from dantrolene-fed (Dan) or vehicle-fed (Veh) APPPS1 mice were stained with anti-A $\beta$ monoclonal antibody and fluorescently labeled secondary lgG. Representative fluorescent images of coronal slices from vehicle-fed and dantrolene-fed APPPS1 mice are shown. $\boldsymbol{B}$, Quantification of average plaque size, pixel intensity, and plaque number in forebrain sections of dantrolene-fed and vehicle-fed APPPS1 mice. a.u., Arbitrary units. The data for each group are shown as mean \pm SE $\left(n=6\right.$ mice). ${ }^{* *} p<0.001$.

sponses were increased in WT hippocampal neurons infected with RyR-shRNAi when compared with neurons infected with Ctrl-shRNAi (Fig. 7C). On average, the size of the $\mathrm{IO}_{30} \mathrm{Ca}^{2+}$ pool was fivefold higher in WT neurons infected with RyR-shRNAi, comparable in size with the $\mathrm{IO}_{30} \mathrm{Ca}^{2+}$ pool in 3xTg neurons (Fig. $7 D$ ). The $3 x T g$ neurons infected with RyR-shRNAi responded to ionomycin more strongly than $3 x \mathrm{Tg}$ neurons infected with CtrlshRNAi (Fig. 7C). On average, the $\mathrm{IO}_{30} \mathrm{Ca}^{2+}$ pool size was three-

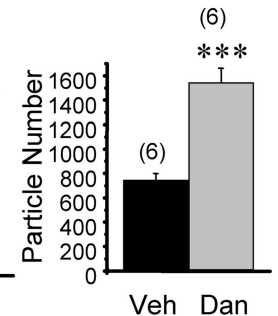

fold larger in 3xTg neurons infected with RyR-shRNAi than in 3xTg neurons infected with Ctrl-shRNAi and $>15$-fold larger than in WT neurons infected with Ctrl-shRNAi (Fig. 7D). From these results, we concluded that RyanRs play a role in the $\mathrm{ER} \mathrm{Ca}^{2+}$ leak pathway in WT hippocampal neurons, but this role becomes more critical in 3xTg hippocampal neurons, which lost $\mathrm{ER} \mathrm{Ca}^{2+}$ leak function of presenilins as a result of the PS1 $1_{\mathrm{M} 146 \mathrm{~V}}$ mutation.

\section{Evaluation of dantrolene in APPPS1 mice}

The results obtained with $3 \times \mathrm{XT}$ hippocampal neurons pointed to a close relationship between presenilin-mediated and RyanRmediated $\mathrm{Ca}^{2+}$ leak pathways (Fig. 7). To understand the importance of this relationship in vivo, we set out to study the effect of dantrolene in an $\mathrm{AD}$ mouse model. For these studies, we focused on APPPS1 double-transgenic mice (Thy1$A P P_{K M 670 / 671 N L}$ and Thy1-PS1 $\left.1_{L 166 P}\right)$ because of the early and robust amyloid accumulation in these mice (Radde et al., 2006; Serneels et al., 2009). Dantrolene was delivered to APPPS1 mice and WT control mice by using an approach that we used previously for dantrolene trials in SCA3 and SCA2 mice (Chen et al., 2008; Liu et al., 2009). In these experiments, six APPPS1 hemizygous female mice and six WT female mice were fed with dantrolene resuspended in PBS with $2 \%$ corn flour. The control group of six APPPS1 hemizygous female mice and six WT female mice were fed with $2 \%$ corn flour in PBS. Littermate mice were selected for four groups to reduce variability. All mice were fed orally twice a week from 2 to 8 months of age and then killed and processed for histological analysis.

To quantify amyloid load in these mice, the coronal slices from both groups of APPPS1 mice were stained with anti-A $\beta$ monoclonal antibody, followed by staining with fluorescently labeled anti-mouse IgG. The stained slices were imaged by using a micrometer resolution laser scanning system. Visual inspection of obtained results indicated that amyloid plaques are more abundant and fluorescent in the dantrolene-fed group of APPPS1 mice than in the control group (Fig. 8A). To quantify these results, we estimated the average number of plaques present in a slice and the average plaque fluorescent signal intensity. From this analysis, we concluded that there was a twofold increase in average plaque number in APPPS1 mice fed with dantrolene when compared with the control group of APPPS1 mice (Fig. $8 B$ ). There was also a twofold increase in average size and fluorescent intensity of amyloid plaques in dantrolene- 
A

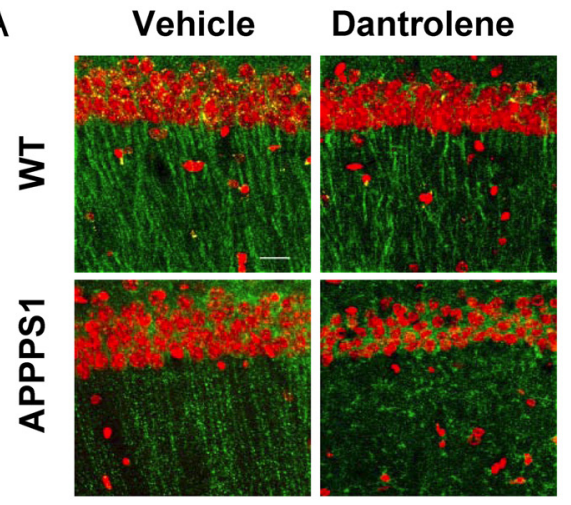

PI PSD95

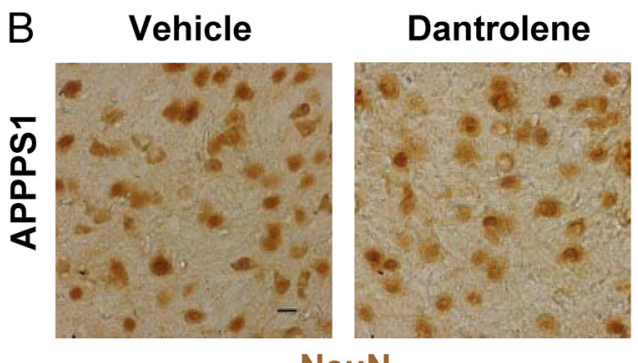

NeuN

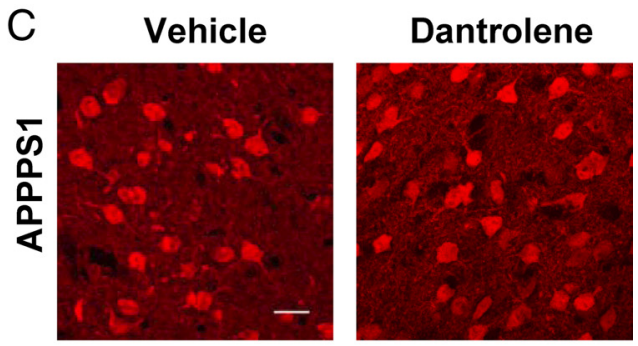

DARPP32

Figure 9. Neuropathological evaluation of long-term dantrolene feeding to APPPS1 mice: synaptic and neuronal markers. $A$, Hippocampal sections from vehicle-fed and dantrolene-fed WT and APPPS1 mice were stained with PI (red) and PSD95 (green) antibodies. Representative images are shown. Scale bar, $20 \mu \mathrm{m}$. B, C, Striatal sections from vehicle-fed and dantrolene-fed APPPS1 mice were stained with NeuN ( $\boldsymbol{C}$ and DARPP-32 (D) monoclonal antibodies. Scale bars, $20 \mu \mathrm{m}$.

fed APPPS1 mice when compared with the control group (Fig. $8 B$ ).

Amyloid load increase in dantrolene-fed APPPS1 mice (Fig. $8 A, B)$ suggested that neuropathological processes may also be accelerated in these mice. To test this hypothesis, we stained hippocampal slices from vehicle-fed and dantrolene-fed APPPS1 mice with antibodies against the excitatory synaptic marker PSD95. Loss of synaptic connections is one of the earliest events in human AD (Selkoe, 2002; Gomez-Isla et al., 2008), and we reasoned that earliest stages of the pathology may be detected by reduction in PSD95 staining. In control experiments, we also performed PSD95 staining of hippocampal slices from vehiclefed and dantrolene-fed WT mice. We discovered that feeding dantrolene resulted in reduction in PSD95 staining density in both WT and APPPS1 mice but that reduction in APPPS1 mice was more severe (Fig. 9A). To compare these results quantitatively, we normalized the PSD95-positive area in hippocampal slices from dantrolene-fed mice to the mean PSD95-positive area in hippocampal slices from vehicle-treated mice from the same group. We found that feeding of dantrolene reduced the PSD95- positive area to $73 \pm 4 \%(n=6)$ of vehicle control in WT mice and to $51 \pm 4 \%(n=6)$ of vehicle control in APPPS1 mice $(p<$ $0.01)$. On average, a number of the PSD95-positive puncta per $100 \mu \mathrm{m}^{2}$ was reduced from $55 \pm 3(n=6)$ in vehicle-treated APPPs1 mice to $21 \pm 2(n=6)$ in dantrolene-fed APPPS1 mice. The number of neuronal cell bodies visualized by PI staining was slightly reduced in the CA1 region of dantrolenefed APPPS1 mice (Fig. 9A). Thus, we concluded that feeding of dantrolene accelerated synaptic loss more significantly than neuronal loss at this early stage of the APPPS1 mice pathology in the hippocampus.

The density of amyloid plaques in dantrolene-fed APPPS1 mice was increased in cortical and hippocampal regions and in basal ganglia (Fig. $8 \mathrm{~A}$ ). Thus, we investigated whether striatal neurons are also affected in these mice. By using the neuronal nuclear marker NeuN and the cytosolic MSN marker DARPP-32, we did not observe significant differences between the control and dantrolene-fed groups of APPPS1 mice (Fig. $9 B, C$ ), suggesting that striatal neurons are not effected in these mice.

To further extend pathological characterization of these mice, we performed silver staining of hippocampal, cortical, and striatal regions from vehicle-fed and dantrolene-fed WT and APPPS1 mice. By using the Bielschowsky staining method, we observed significant reduction in neuronal fiber density and abundance of dystrophic neurites in hippocampal and cortical regions of dantrolene-fed APPPS1 mice (Fig. 10). Quantitative analysis of silver staining data revealed that the neurites occupied $42 \pm 3 \%$ $(n=6)$ of surface area in hippocampal sections from the control group and only $31 \pm 2 \%(n=6)$ in the dantrolene-fed group. We also observed significant thinning of the CA1 cell body layer in the hippocampus and appearance of many spaces without cell bodies in the hippocampal and cortical neuropil of dantrolenefed mice (Fig. 10). All of these changes were consistent with ongoing neuronal atrophy and neuronal loss in hippocampal and cortical regions of dantrolene-fed APPPS1 mice. Consistent with the immunostaining data (Fig. $9 C, D$ ), silver staining showed that striatal MSNs were not affected in dantrolene-fed APPPS1 mice but that the cortical projection fibers were undergoing dystrophic changes (Fig. 10). The observed effects were specific for APPPS1 mice, because no significant abnormalities were observed in hippocampal, cortical, or striatal regions of dantrolene-fed WT mice (Fig. 10).

\section{Discussion}

Presenilins function as neuronal $\mathrm{ER} \mathrm{Ca}^{2+}$ leak channels In the previous studies with MEF cells from PS DKO mice, we discovered that presenilins control $\mathrm{ER} \mathrm{Ca}^{2+}$ levels by acting as passive ER $\mathrm{Ca}^{2+}$ leak channels (Tu et al., 2006). We further demonstrated that many FAD mutations in presenilins result in loss of ${\mathrm{ER} \mathrm{Ca}^{2+}}^{2+}$ leak function, leading to $\mathrm{ER} \mathrm{Ca}^{2+}$ overload and supranormal $\mathrm{Ca}^{2+}$ release from the ER (Tu et al., 2006; Nelson et al., 2007, 2010). Our hypothesis has been challenged based on experiments with PS-transfected Xenopus oocytes and the chicken B-cell DT40 cell line (Cheung et al., 2008). As an alternative explanation, Cheung et al. proposed that FAD mutant presenilins affect $\mathrm{Ca}^{2+}$ signaling by modulating channel openings of $\mathrm{InsP}_{3} \mathrm{R} 1$ and not by changing $\mathrm{ER} \mathrm{Ca}^{2+}$ levels (Cheung et al., 2008). Results obtained in the present study strongly support our hypothesis that presenilins in fact function as $\mathrm{ER} \mathrm{Ca}^{2+}$ leak channels. In experiments with hippocampal neuronal cultures from 3xTg and PScDKO mice, we demonstrated that $\mathrm{PS}_{\mathrm{M} 146 \mathrm{~V}}$ mutation or genetic deletion of presenilins resulted in enhanced caffeine-induced $\mathrm{Ca}^{2+}$ release from the ER (Fig. 1), increase in 

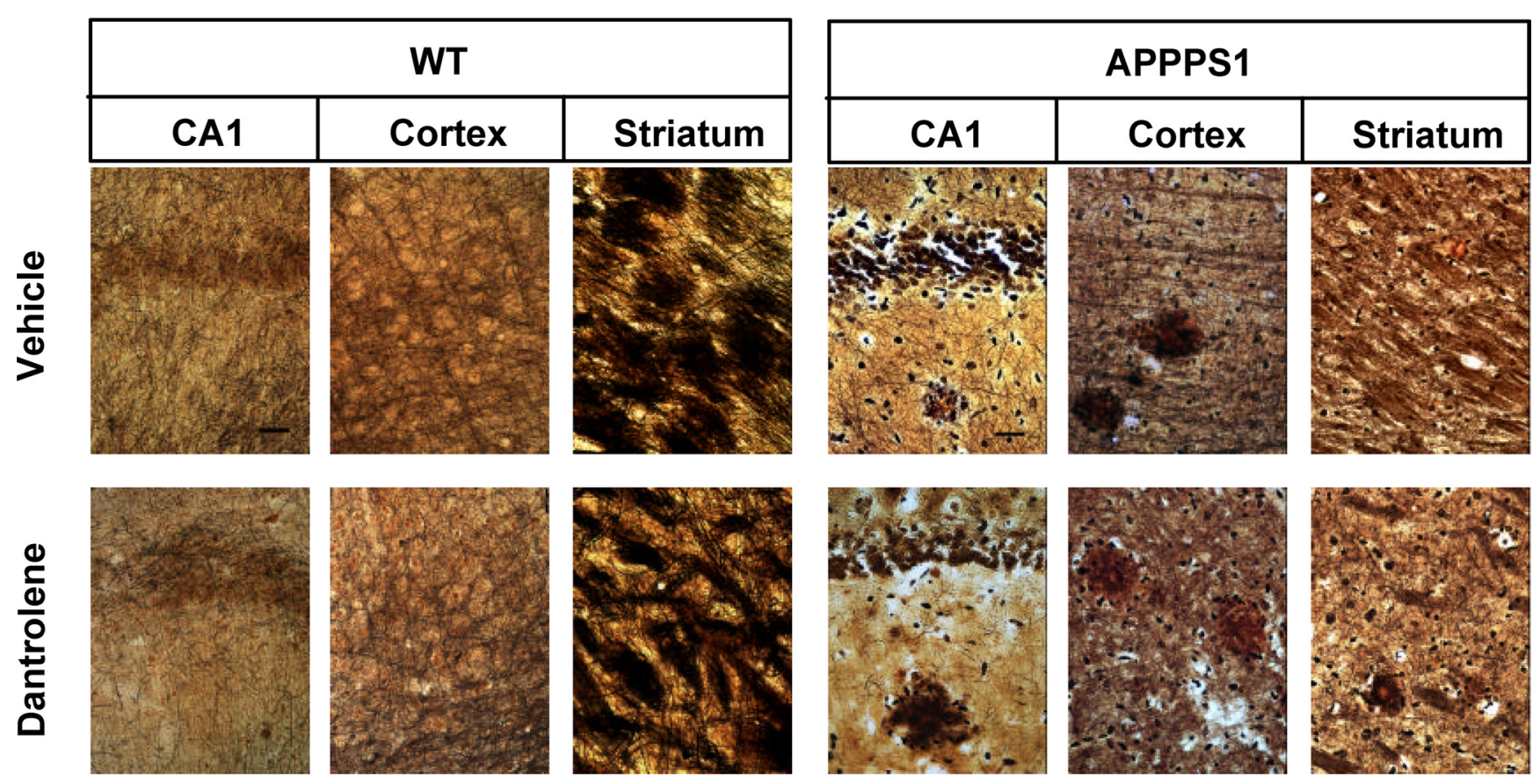

Figure 10. Neuropathological evaluation of long-term dantrolene feeding to APPPS1 mice: silver staining. Hippocampal, cortical, and striatal sections from vehicle-fed and dantrolene-fed WT and APPPS1 mice were stained using Bielschowsky silver stain. Representative images are shown. Scale bars, $20 \mu \mathrm{m}$.

the size of ionomycin-sensitive $\mathrm{Ca}^{2+}$ pool (Fig. 2), increased ER $\mathrm{Ca}^{2+}$ levels (Fig. 3), reduced store-operated $\mathrm{Ca}^{2+}$ entry (Fig. 4), and decreased passive ER $\mathrm{Ca}^{2+}$ leak rate (Fig. 5). The defects in $\mathrm{Ca}^{2+}$ signaling observed in PS DKO hippocampal neurons could be rescued by expression of wild-type PS1 or PS1-D257A mutant deficient in $\gamma$-secretase activity but not by PS1-L166P or PS1M146V FAD mutants deficient in $\mathrm{ER} \mathrm{Ca}^{2+}$ leak channel activity or PS1-D385A mutant deficient in both $\gamma$-secretase and ER Ca ${ }^{2+}$ leak activities (Figs. 1, 2, 5). From these results, we concluded that presenilins function as ER $\mathrm{Ca}^{2+}$ leak channels in hippocampal neurons, a function independent from their $\gamma$-secretase activity (Fig. 11A). Our results provide a coherent explanation for numerous previous reports of abnormal $\mathrm{Ca}^{2+}$ signaling observed in hippocampal and cortical neurons expressing PS1 or PS2 FAD mutants (Begley et al., 1999; Guo et al., 1999; Chan et al., 2000; Yoo et al., 2000; Schneider et al., 2001; Herms et al., 2003; Stutzmann et al., 2004, 2006; Smith et al., 2005; Chakroborty et al., 2009). The main findings reported in these studies, such as enhanced $\mathrm{ER} \mathrm{Ca}^{2+}$ release via $\mathrm{InsP}_{3} \mathrm{R}$ and RyanR and impaired SOC, can be accounted for by the loss of $\mathrm{ER} \mathrm{Ca}^{2+}$ leak function of presenilins and overloaded $\mathrm{ER} \mathrm{Ca}^{2+}$ stores. The same mechanism may also contribute to abnormal presynaptic ER $\mathrm{Ca}^{2+}$ signaling and impaired $\mathrm{Ca}^{2+}$ dependent synaptic plasticity in PS DKO hippocampal neurons (Zhang et al., 2009).

Interestingly, the ER membrane of striatal MSNs is much less leaky for $\mathrm{Ca}^{2+}$ than ER membrane of hippocampal neurons, and presenilins appear to play a lesser role in controlling ER $\mathrm{Ca}^{2+}$ homeostasis in MSNs than in hippocampal neurons (Fig. 6). Fulllength PS1 is present in relatively lower amounts in MSNs when compared with hippocampal neurons (Fig. 6D), providing a possible biochemical explanation to these findings. In contrast to hippocampal and cortical neurons, striatal MSNs are not affected in AD (Gomez-Isla et al., 2008), and future studies will be needed to further investigate whether a correlation exists between the potency of the ER $\mathrm{Ca}^{2+}$ leak pathway and selective vulnerability of different neuronal populations in $\mathrm{AD}$.
Presenilins, ryanodine receptors, and neuronal

\section{$\mathrm{Ca}^{2+}$ homeostasis}

An increase in RyanR expression levels has been reported previously for $3 \mathrm{xTg}$ and $K I-P S 1_{M 146 V}$ hippocampal and cortical neurons (Chan et al., 2000; Smith et al., 2005; Stutzmann et al., 2006; Chakroborty et al., 2009). We have also observed a significant increase in RyanR expression levels in 3xTg hippocampal neuronal cultures (Fig. 1D) (supplemental Fig. 2, available at www.jneurosci. org as supplemental material). The increase in RyanR expression levels has been proposed previously to be responsible for enhanced caffeine-induced $\mathrm{Ca}^{2+}$ responses in $3 \times \mathrm{Tg}$ and $\mathrm{KI}-$ $P S 1_{M 146 V}$ neurons (Chan et al., 2000; Smith et al., 2005; Stutzmann et al., 2006; Chakroborty et al., 2009). We would like to revise this view and suggest that the increase in RyanR levels plays a compensatory role for the loss of presenilin leak function. Our experiments with RyR-shRNAi indicated that, in wild-type hippocampal neurons, RyanRs contribute to the $\mathrm{ER} \mathrm{Ca}^{2+}$ leak function (Fig. $11 \mathrm{~A}$ ). In $3 \mathrm{xTg}$ hippocampal neurons, the $\mathrm{PS} 1_{\mathrm{M} 146 \mathrm{~V}}$ mutation impairs presenilin-mediated $\mathrm{ER} \mathrm{Ca}^{2+}$ leak and the role of RyanR becomes more critical. Most likely, an increase in RyanR expression levels is an attempt by 3xTg hippocampal neurons to boost the RyanR-mediated $\mathrm{Ca}^{2+}$ leak pathway, which would then conceivably compensate for the loss of presenilinmediated $\mathrm{ER} \mathrm{Ca}^{2+}$ leak more efficiently (Fig. $11 \mathrm{~B}$ ). The sensitivity of RyanRs to cytosolic $\mathrm{Ca}^{2+}$ is known to be modulated by ER $\mathrm{Ca}^{2+}$ levels. When ER $\mathrm{Ca}^{2+}$ levels become too high, even basal cytosolic $\mathrm{Ca}^{2+}$ levels become sufficient to result in RyanR opening. This is the so-called "store-overload-induced $\mathrm{Ca}^{2+}$ release" (SOICR) mechanism, which has been well described in cardiac cells (Jiang et al., 2004; Jones et al., 2008). We postulate that a similar SOICR mechanism supported by RyanRs is also functional in neurons, in particular in the condition of impaired ER $\mathrm{Ca}^{2+}$ leak, such as that attributable to PS FAD mutations.

If RyanR-mediated $\mathrm{Ca}^{2+}$ leak is inhibited in this situation (by dantrolene or by RyR-shRNAi knockdown of RyanR expression), then ${\mathrm{ER} \mathrm{Ca}^{2+}}^{2}$ stores become very full, with total $\mathrm{ER} \mathrm{Ca}^{2+}$ 
content 10- to 15 -fold higher than in wildtype cells (Fig. 11C). Resulting $\mathrm{Ca}^{2+}$ dyshomeostasis likely affects other neuronal functions, such as synaptic transmission and plasticity (Chakroborty et al., 2009). Addition studies will be required to understand the mechanism involved in upregulation of RyanR resulting from PS1 FAD mutations. A threefold increase in RyanR2 mRNA has been discovered in samples extracted from adult hippocampus of 3xTg mice (Chakroborty et al., 2009), and a fourfold increase in RyanR3 mRNA was reported for samples from $K I-P S 1_{M 146 V}$ adult mice hippocampus (Chan et al., 2000). We have also observed a twofold to threefold increase in RyanR2 and RyanR3 mRNA in quantitative PCR experiments with $3 \times \mathrm{Tg}$ hippocampal neuronal cultures (data not shown). These results suggest that impaired $\mathrm{ER} \mathrm{Ca}^{2+}$ leak function and increased ER $\mathrm{Ca}^{2+}$ levels are linked with an increase in transcription of genes encoding RyanR2 and RyanR3 via an "ER $\mathrm{Ca}^{2+}$ homeostasis"-negative feedback mechanism. The molecular underpinnings of this feedback mechanism need to be clarified in addition studies.

\section{Protective role of ryanodine receptors in Alzheimer's disease}

Our results indicate that RyanRs may play a protective role in the context of $\mathrm{AD}$. The $\mathrm{Ca}^{2+}$ homeostasis model that we propose (Fig. 11) predicts that blocking RyanRs in AD could have a disastrous effect on the pathology. We tested this hypothesis by longterm feeding of dantrolene to APPPS1 mice. We discovered that long-term feeding of dantrolene to APPPS1 mice results in threefold increase in amyloid load (Fig. $8 A, B$ ), loss of excitatory markers of synaptic transmission in hippocampus (Fig. 9A), and neuronal atrophy and loss in hippocampus and cortex (Fig. 10). The results with dantrolene are somewhat paradoxical, because high $(1-10 \mu \mathrm{M})$ concentrations of dantrolene reduced glutamateinduced excitotoxicity in $K I-P S 1_{M 146 V}$ mouse hippocampal neurons (Guo et al., 1999). We obtained similar results in studies with 3xTg hippocampal neuronal cultures (data not shown). Moreover, we reported previously that long-term feeding of dantrolene to SCA 3 and SCA 2 mouse models slowed progression of motor phenotype and alleviated age-dependent neuronal loss in these mice (Chen et al., 2008; Liu et al., 2009). These results suggest that, although in general dantrolene acts as an antiexcitotoxic agent, it specifically accelerated pathology in APPPS1 mice. These results agree with our hypothesis that the loss of ER $\mathrm{Ca}^{2+}$ leak function of presenilins in APPPS1 mice (attributable to the $P S 1_{L 166 \mathrm{P}}$ mutation) is compensated by increased RyanRmediated $\mathrm{Ca}^{2+}$ flux from the ER. Blocking RyanRs by dantrolene in this situation leads to an addition increase in neuronal ER $\mathrm{Ca}^{2+}$ levels and accelerated pathology (Fig. 11C).

Interestingly, the potentially protective role of RyanRs has been proposed previously based on studies of APP transgenic mice (TgCRND8 mice; $\left.\operatorname{Pr} P-A P P_{K M 670 / 671 N L}\right)$. These investigators discovered that the levels of RyanR3 mRNA and protein are significantly increased in the cortex of adult TgCRND8 mice and in TgCRND8 cortical neuronal cultures (Supnet et al., 2006). Moreover, direct exposure of wild-type cortical neuronal cultures to $\mathrm{A} \beta_{42}$ resulted in 3.5-fold increase in RyanR3 mRNA levels (Supnet et al., 2010). These effects were specific for RyanR3, because exposure to $\mathrm{A} \beta_{42}$ did not affect expression levels of RyanR2, InsP $_{3}$ R1, or SERCA2b (Supnet et al., 2006). Formation of amyloid plaques and accumulation of extracellular $A \beta_{42}$ causes destabilization of neuronal $\mathrm{Ca}^{2+}$ signals and increase in neuronal excitability (Busche et al., 2008; Kuchibhotla et al., 2008), and Supnet at al. (2006) argued that upregulation of RyanR3 could be a compensatory response aimed to protect against increased cortical neurons excitability and abnormal $\mathrm{Ca}^{2+}$ signals induced by $\mathrm{A} \beta_{42}$ exposure. Consistent with this prediction, the same authors recently discovered that knockdown of RyanR3 by RNAi accelerated neuronal death of TgCRND8 cultured cortical neurons but not wild-type cultured cortical neurons (Supnet et al., 2010). Thus, upregulation of RyanRs may have protective effects in both mutant presenilin and mutant APP models of AD, as we discussed recently (Supnet and Bezprozvanny, 2010).

\section{Neuronal $\mathrm{Ca}^{2+}$ signaling, amyloid accumulation, and AD pathology}

Our main goal was to define the role played by presenilins in the neuronal $\mathrm{ER} \mathrm{Ca}^{2+}$ leak pathway. In addition to this specific issue, some of our results have implications for the more general understanding of existing connections between neuronal $\mathrm{Ca}^{2+}$ signaling, amyloid accumulation, and neuronal pathology in AD. A few previous studies addressed potential connections between $\mathrm{Ca}^{2+}$ signaling and amyloid production (Green et al., 2007). Some of these studies concluded that increased cytosolic $\mathrm{Ca}^{2+}$ signals enhance production of $\mathrm{A} \beta_{42}$ and increase the $\mathrm{A} \beta_{42} / \mathrm{A} \beta_{40}$ ratio (Querfurth and Selkoe, 1994; Pierrot et al., 2004; Green et al., 2007). Other studies indicated that increased $\mathrm{Ca}^{2+}$ signals reduce production of $\mathrm{A} \beta_{42}$ and reduce the $\mathrm{A} \beta_{42} / \mathrm{A} \beta_{40}$ ratio (Dreses-Werringloer et al., 2008). Most of these studies have been performed in non-neuronal systems. In our experiments, we observed twofold to threefold increases in amyloid load in dantrolene-fed APPPS1 mice (Fig. 8A,B). Although the exact mechanism responsible for these effects still needs to be clarified, these results suggest that abnormal $\mathrm{ER} \mathrm{Ca}^{2+}$ signaling is able to drive amyloid accumulation in the brain.

Cortical and hippocampal neuronal atrophy is typical of human AD (Gomez-Isla et al., 1996; Price et al., 2001; Gómez-Isla et al., 2008) and correlates much better with cognitive decline than 
the amyloid load (Giannakopoulos et al., 2003; Gómez-Isla et al., 2008). However, neuronal atrophy has been very difficult to reproduce in APP and presenilin transgenic mouse modes (Takeuchi et al., 2000; Schwab et al., 2004; Gómez-Isla et al., 2008). Interestingly, we found that feeding of dantrolene to APPPS1 mice resulted in significant loss of hippocampal excitatory synaptic markers (Fig. $9 A)$ and in neuronal atrophy in hippocampal and cortical regions (Fig. 10). Despite comparable increases in amyloid load in the striatal region (Fig. $8 A$ ), striatal MSNs were not significantly affected by dantrolene feeding to APPPS1 mice (Figs. 9B, $C, 10$ ). As discussed above, the $\mathrm{ER} \mathrm{Ca}^{2+}$ leak pathway is less potent in striatal MSNs than in hippocampal neurons, which may explain why striatal neurons are less affected when the $\mathrm{ER} \mathrm{Ca}^{2+}$ leak pathway is impaired by combined effects of PS1 $1_{\mathrm{L} 166 \mathrm{P}}$ mutation and dantrolene feeding in APPPS1 mice.

In conclusion, here we report analysis of the role played by presenilins in neuronal $\mathrm{Ca}^{2+}$ signaling. We conclude that presenilins function as $\mathrm{ER} \mathrm{Ca}^{2+}$ leak channels in hippocampal neurons and that the loss of ER $\mathrm{Ca}^{2+}$ leak function of presenilins was partially compensated by an increase in RyanR expression. We further found that, if both PS-mediated and RyanR-mediated $\mathrm{ER} \mathrm{Ca}^{2+}$ leak pathways are impaired, then ER $\mathrm{Ca}^{2+}$ levels in hippocampal neurons increase dramatically. Simultaneous block of both PS-mediated and RyanR-mediated ER Ca ${ }^{2+}$ leak pathways in vivo resulted in an increase in amyloid accumulation, loss of synaptic markers in hippocampus, and neuronal atrophy in hippocampus and cortex. Our results further support a close connection between neuronal $\mathrm{Ca}^{2+}$ signaling, amyloid accumulation, and AD pathogenesis (Bezprozvanny and Mattson, 2008).

\section{References}

Akbari Y, Hitt BD, Murphy MP, Dagher NN, Tseng BP, Green KN, Golde TE, LaFerla FM (2004) Presenilin regulates capacitative calcium entry dependently and independently of gamma-secretase activity. Biochem Biophys Res Commun 322:1145-1152.

Annaert WG, Levesque L, Craessaerts K, Dierinck I, Snellings G, Westaway D, George-Hyslop PS, Cordell B, Fraser P, De Strooper B (1999) Presenilin 1 controls gamma-secretase processing of amyloid precursor protein in pre-golgi compartments of hippocampal neurons. J Cell Biol 147:277-294.

Begley JG, Duan W, Chan S, Duff K, Mattson MP (1999) Altered calcium homeostasis and mitochondrial dysfunction in cortical synaptic compartments of presenilin-1 mutant mice. J Neurochem 72:1030-1039.

Bezprozvanny I, Mattson MP (2008) Neuronal calcium mishandling and the pathogenesis of Alzheimer's disease. Trends Neurosci 31:454-463.

Busche MA, Eichhoff G, Adelsberger H, Abramowski D, Wiederhold KH, Haass C, Staufenbiel M, Konnerth A, Garaschuk O (2008) Clusters of hyperactive neurons near amyloid plaques in a mouse model of Alzheimer's disease. Science 321:1686-1689.

Cai C, Lin P, Cheung KH, Li N, Levchook C, Pan Z, Ferrante C, Boulianne GL, Foskett JK, Danielpour D, Ma J (2006) The presenilin-2 loop peptide perturbs intracellular $\mathrm{Ca}^{2+}$ homeostasis and accelerates apoptosis. J Biol Chem 281:16649-16655.

Chakroborty S, Goussakov I, Miller MB, Stutzmann GE (2009) Deviant ryanodine receptor-mediated calcium release resets synaptic homeostasis in presymptomatic 3xTg-AD mice. J Neurosci 29:9458-9470.

Chan SL, Mayne M, Holden CP, Geiger JD, Mattson MP (2000) Presenilin-1 mutations increase levels of ryanodine receptors and calcium release in PC12 cells and cortical neurons. J Biol Chem 275:18195-18200.

Chen X, Tang TS, Tu H, Nelson O, Pook M, Hammer R, Nukina N, Bezprozvanny I (2008) Deranged calcium signaling and neurodegeneration in spinocerebellar ataxia type 3. J Neurosci 28:12713-12724.

Cheung KH, Shineman D, Müller M, Cárdenas C, Mei L, Yang J, Tomita T, Iwatsubo T, Lee VM, Foskett JK (2008) Mechanism of $\mathrm{Ca}^{2+}$ disruption in Alzheimer's disease by presenilin regulation of InsP(3) receptor channel gating. Neuron 58:871-883.

De Strooper B, Saftig P, Craessaerts K, Vanderstichele H, Guhde G, Annaert
W, Von Figura K, Van Leuven F (1998) Deficiency of presenilin-1 inhibits the normal cleavage of amyloid precursor protein. Nature 391:387-390.

Dreses-Werringloer U, Lambert JC, Vingtdeux V, Zhao H, Vais H, Siebert A, Jain A, Koppel J, Rovelet-Lecrux A, Hannequin D, Pasquier F, Galimberti D, Scarpini E, Mann D, Lendon C, Campion D, Amouyel P, Davies P, Foskett JK, Campagne F, Marambaud P (2008) A polymorphism in CALHM1 influences $\mathrm{Ca}^{2+}$ homeostasis, A beta levels, and Alzheimer's disease risk. Cell 133:1149-1161.

Giannakopoulos P, Herrmann FR, Bussière T, Bouras C, Kövari E, Perl DP, Morrison JH, Gold G, Hof PR (2003) Tangle and neuron numbers, but not amyloid load, predict cognitive status in Alzheimer's disease. Neurology 60:1495-1500.

Gómez-Isla T, Price JL, McKeel DW Jr, Morris JC, Growdon JH, Hyman BT (1996) Profound loss of layer II entorhinal cortex neurons occurs in very mild Alzheimer's disease. J Neurosci 16:4491-4500.

Gomez-Isla T, Spires T, De Calignon A, Hyman BT (2008) Neuropathology of Alzheimer's disease. Handb Clin Neurol 89:233-243.

Green KN, Smith IF, Laferla FM (2007) Role of calcium in the pathogenesis of Alzheimer's disease and transgenic models. Subcell Biochem 45:507-521.

Green KN, Demuro A, Akbari Y, Hitt BD, Smith IF, Parker I, LaFerla FM (2008) SERCA pump activity is physiologically regulated by presenilin and regulates amyloid beta production. J Cell Biol 181:1107-1116.

Guo Q, Fu W, Sopher BL, Miller MW, Ware CB, Martin GM, Mattson MP (1999) Increased vulnerability of hippocampal neurons to excitotoxic necrosis in presenilin-1 mutant knock-in mice. Nat Med 5:101-106.

Hayrapetyan V, Rybalchenko V, Rybalchenko N, Koulen P (2008) The $\mathrm{N}$-terminus of presenilin-2 increases single channel activity of brain ryanodine receptors through direct protein-protein interaction. Cell Calcium 44:507-518.

Herms J, Schneider I, Dewachter I, Caluwaerts N, Kretzschmar H, Van Leuven F (2003) Capacitive calcium entry is directly attenuated by mutant presenilin-1, independent of the expression of the amyloid precursor protein. J Biol Chem 278:2484-2489.

Herreman A, Hartmann D, Annaert W, Saftig P, Craessaerts K, Serneels L, Umans L, Schrijvers V, Checler F, Vanderstichele H, Baekelandt V, Dressel R, Cupers P, Huylebroeck D, Zwijsen A, Van Leuven F, De Strooper B (1999) Presenilin 2 deficiency causes a mild pulmonary phenotype and no changes in amyloid precursor protein processing but enhances the embryonic lethal phenotype of presenilin 1 deficiency. Proc Natl Acad Sci U S A 96:11872-11877.

Herreman A, Serneels L, Annaert W, Collen D, Schoonjans L, De Strooper B (2000) Total inactivation of gamma-secretase activity in presenilindeficient embryonic stem cells. Nat Cell Biol 2:461-462.

Ito E, Oka K, Etcheberrigaray R, Nelson TJ, McPhie DL, Tofel-Grehl B, Gibson GE, Alkon DL (1994) Internal $\mathrm{Ca}^{2+}$ mobilization is altered in fibroblasts from patients with Alzheimer disease. Proc Natl Acad Sci U S A 91:534-538.

Jiang D, Xiao B, Yang D, Wang R, Choi P, Zhang L, Cheng H, Chen SR (2004) RyR2 mutations linked to ventricular tachycardia and sudden death reduce the threshold for store-overload-induced $\mathrm{Ca}^{2+}$ release (SOICR). Proc Natl Acad Sci U S A 101:13062-13067.

Jones PP, Jiang D, Bolstad J, Hunt DJ, Zhang L, Demaurex N, Chen SR (2008) Endoplasmic reticulum $\mathrm{Ca}^{2+}$ measurements reveal that the cardiac ryanodine receptor mutations linked to cardiac arrhythmia and sudden death alter the threshold for store-overload-induced $\mathrm{Ca}^{2+}$ release. Biochem J 412:171-178.

Kaznacheyeva E, Lupu VD, Bezprozvanny I (1998) Single-channel properties of inositol $(1,4,5)$-trisphosphate receptor heterologously expressed in HEK-293 cells. J Gen Physiol 111:847-856.

Krause T, Gerbershagen MU, Fiege M, Weisshorn R, Wappler F (2004) Dantrolene: a review of its pharmacology, therapeutic use and new developments. Anaesthesia 59:364-373.

Kuchibhotla KV, Goldman ST, Lattarulo CR, Wu HY, Hyman BT, Bacskai BJ (2008) Abeta plaques lead to aberrant regulation of calcium homeostasis in vivo resulting in structural and functional disruption of neuronal networks. Neuron 59:214-225.

Laudon H, Hansson EM, Melén K, Bergman A, Farmery MR, Winblad B, Lendahl U, von Heijne G, Näslund J (2005) A nine-transmembrane domain topology for presenilin 1. J Biol Chem 280:35352-35360.

Leissring MA, Parker I, LaFerla FM (1999a) Presenilin-2 mutations modu- 
late amplitude and kinetics of inositol 1, 4,5-trisphosphate-mediated calcium signals. J Biol Chem 274:32535-32538.

Leissring MA, Paul BA, Parker I, Cotman CW, LaFerla FM (1999b) Alzheimer's presenilin-1 mutation potentiates inositol 1,4,5-trisphosphate-mediated calcium signaling in Xenopus oocytes. J Neurochem 72:1061-1068.

Leissring MA, Akbari Y, Fanger CM, Cahalan MD, Mattson MP, LaFerla FM (2000) Capacitative calcium entry deficits and elevated luminal calcium content in mutant presenilin-1 knockin mice. J Cell Biol 149:793-798.

Liu J, Tang TS, Tu H, Nelson O, Herndon E, Huynh DP, Pulst SM, Bezprozvanny I (2009) Deranged calcium signaling and neurodegeneration in spinocerebellar ataxia type 2. J Neurosci 29:9148-9162.

McCombs JE, Palmer AE (2008) Measuring calcium dynamics in living cells with genetically encodable calcium indicators. Methods 46:152-159.

Nelson O, Tu H, Lei T, Bentahir M, de Strooper B, Bezprozvanny I (2007) Familial Alzheimer disease-linked mutations specifically disrupt $\mathrm{Ca}^{2+}$ leak function of presenilin 1. J Clin Invest 117:1230-1239.

Nelson O, Supnet C, Liu H, Bezprozvanny I (2010) Familial Alzheimer's disease mutations in presenilins: effects on endoplasmic reticulum calcium homeostasis and correlation with clinical phenotypes. J Alzheimers Dis, in press.

Oddo S, Caccamo A, Shepherd JD, Murphy MP, Golde TE, Kayed R, Metherate R, Mattson MP, Akbari Y, LaFerla FM (2003) Triple-transgenic model of Alzheimer's disease with plaques and tangles: intracellular Abeta and synaptic dysfunction. Neuron 39:409-421.

Palmer AE, Jin C, Reed JC, Tsien RY (2004) Bcl-2-mediated alterations in endoplasmic reticulum $\mathrm{Ca}^{2+}$ analyzed with an improved genetically encoded fluorescent sensor. Proc Natl Acad Sci U S A 101:17404-17409.

Pierrot N, Ghisdal P, Caumont AS, Octave JN (2004) Intraneuronal amyloidbeta1-42 production triggered by sustained increase of cytosolic calcium concentration induces neuronal death. J Neurochem 88:1140-1150.

Price JL, Ko AI, Wade MJ, Tsou SK, McKeel DW, Morris JC (2001) Neuron number in the entorhinal cortex and CA1 in preclinical Alzheimer disease. Arch Neurol 58:1395-1402.

Querfurth HW, Selkoe DJ (1994) Calcium ionophore increases amyloid beta peptide production by cultured cells. Biochemistry 33:4550-4561.

Radde R, Bolmont T, Kaeser SA, Coomaraswamy J, Lindau D, Stoltze L, Calhoun ME, Jäggi F, Wolburg H, Gengler S, Haass C, Ghetti B, Czech C, Hölscher C, Mathews PM, Jucker M (2006) Abeta42-driven cerebral amyloidosis in transgenic mice reveals early and robust pathology. EMBO Rep 7:940-946.

Rybalchenko V, Hwang SY, Rybalchenko N, Koulen P (2008) The cytosolic $\mathrm{N}$-terminus of presenilin-1 potentiates mouse ryanodine receptor single channel activity. Int J Biochem Cell Biol 40:84-97.

Schneider I, Reverse D, Dewachter I, Ris L, Caluwaerts N, Kuiperi C, Gilis M, Geerts H, Kretzschmar H, Godaux E, Moechars D, Van Leuven F, Herms J (2001) Mutant presenilins disturb neuronal calcium homeostasis in the brain of transgenic mice, decreasing the threshold for excitotoxicity and facilitating long-term potentiation. J Biol Chem 276:11539-11544.

Schwab C, Hosokawa M, McGeer PL (2004) Transgenic mice overexpressing amyloid beta protein are an incomplete model of Alzheimer disease. Exp Neurol 188:52-64.

Selkoe DJ (2002) Alzheimer's disease is a synaptic failure. Science 298:789-791.

Serneels L, Van Biervliet J, Craessaerts K, Dejaegere T, Horré K, Van Houtvin T, Esselmann H, Paul S, Schäfer MK, Berezovska O, Hyman BT, Sprangers B, Sciot R, Moons L, Jucker M, Yang Z, May PC, Karran E, Wiltfang J, D'Hooge R, De Strooper B (2009) gamma-Secretase heterogeneity in the Aph1 subunit: relevance for Alzheimer's disease. Science 324:639642.

Smith IF, Hitt B, Green KN, Oddo S, LaFerla FM (2005) Enhanced caffeine- induced $\mathrm{Ca}^{2+}$ release in the $3 \times \mathrm{Tg}-\mathrm{AD}$ mouse model of Alzheimer's disease. J Neurochem 94:1711-1718.

Spasic D, Tolia A, Dillen K, Baert V, De Strooper B, Vrijens S, Annaert W (2006) Presenilin-1 maintains a nine-transmembrane topology throughout the secretory pathway. J Biol Chem 281:26569-26577.

Stutzmann GE, Caccamo A, LaFerla FM, Parker I (2004) Dysregulated IP3 signaling in cortical neurons of knock-in mice expressing an Alzheimer'slinked mutation in presenilin1 results in exaggerated $\mathrm{Ca}^{2+}$ signals and altered membrane excitability. J Neurosci 24:508-513.

Stutzmann GE, Smith I, Caccamo A, Oddo S, Laferla FM, Parker I (2006) Enhanced ryanodine receptor recruitment contributes to $\mathrm{Ca}^{2+}$ disruptions in young, adult, and aged Alzheimer's disease mice. J Neurosci 26:5180-5189.

Supnet C, Bezprozvanny I (2010) The dysregulation of intracellular calcium in Alzheimer disease. Cell Calcium 47:183-189.

Supnet C, Grant J, Kong H, Westaway D, Mayne M (2006) Amyloid-beta(1-42) increases ryanodine receptor-3 expression and function in neurons of TgCRND8 mice. J Biol Chem 281:38440-38447.

Supnet C, Noonan C, Richard K, Bradley J, Mayne M (2010) Up-regulation of the type 3 ryanodine receptor is neuroprotective in the TgCRND8 mouse model of Alzheimer's disease. J Neurochem 112:356-365.

Takeuchi A, Irizarry MC, Duff K, Saido TC, Hsiao Ashe K, Hasegawa M, Mann DM, Hyman BT, Iwatsubo T (2000) Age-related amyloid beta deposition in transgenic mice overexpressing both Alzheimer mutant presenilin 1 and amyloid beta precursor protein Swedish mutant is not associated with global neuronal loss. Am J Pathol 157:331-339.

Tandon A, Fraser P (2002) The presenilins. Genome Biol 3:reviews3014.

Tang TS, Slow E, Lupu V, Stavrovskaya IG, Sugimori M, Llinás R, Kristal BS, Hayden MR, Bezprozvanny I (2005) Disturbed $\mathrm{Ca}^{2+}$ signaling and apoptosis of medium spiny neurons in Huntington's disease. Proc Natl Acad Sci U S A 102:2602-2607.

Tang TS, Guo C, Wang H, Chen X, Bezprozvanny I (2009) Neuroprotective effects of inositol 1,4,5-trisphosphate receptor C-terminal fragment in a Huntington's disease mouse model. J Neurosci 29:1257-1266.

Tu H, Nelson O, Bezprozvanny A, Wang Z, Lee SF, Hao YH, Serneels L, De Strooper B, Yu G, Bezprozvanny I (2006) Presenilins form ER calcium leak channels, a function disrupted by mutations linked to familial Alzheimer's disease. Cell 126:981-993.

Venkatachalam K, van Rossum DB, Patterson RL, Ma HT, Gill DL (2002) The cellular and molecular basis of store-operated calcium entry. Nat Cell Biol 4:E263-E272.

Vonsattel JP, DiFiglia M (1998) Huntington disease. J Neuropathol Exp Neurol 57:369-384.

Wolfe MS, Xia W, Ostaszewski BL, Diehl TS, Kimberly WT, Selkoe DJ (1999) Two transmembrane aspartates in presenilin-1 required for presenilin endoproteolysis and gamma-secretase activity. Nature 398:513-517.

Yoo AS, Cheng I, Chung S, Grenfell TZ, Lee H, Pack-Chung E, Handler M, Shen J, Xia W, Tesco G, Saunders AJ, Ding K, Frosch MP, Tanzi RE, Kim TW (2000) Presenilin-mediated modulation of capacitative calcium entry. Neuron 27:561-572.

Zhang C, Wu B, Beglopoulos V, Wines-Samuelson M, Zhang D, Dragatsis I, Südhof TC, Shen J (2009) Presenilins are essential for regulating neurotransmitter release. Nature 460:632-636.

Zhang H, Fu Y, Altier C, Platzer J, Surmeier DJ, Bezprozvanny I (2006) CaV1.2 and CaV1.3 neuronal L-type calcium channels: differential targeting and signaling to pCREB. Eur J Neurosci 23:2297-2310.

Zhao X, Weisleder N, Han X, Pan Z, Parness J, Brotto M, Ma J (2006) Azumolene inhibits a component of store-operated calcium entry coupled to the skeletal muscle ryanodine receptor. J Biol Chem 281:33477-33486. 